\title{
Geografía del terror: homicidios y desapariciones forzadas en los municipios de México 2006-2017
}

\section{Geography of terror: Homicides and enforced disappearances in the municipalities of Mexico 2006-2017}

\author{
Edel Cadena y Carlos Garrocho \\ Facultad de Geografía, Universidad Autónoma del Estado de México, México \\ El Colegio Mexiquense, México
}

\begin{abstract}
Resumen
Los objetivos de este trabajo son: i) develar la dinámica de los homicidios y las desapariciones forzadas en México, sus entidades federativas y en los dos mil 458 municipios del país; ii) descubrir el patrón espacial de los homicidios y desapariciones en la escala municipal de México en términos de su intensidad y aglomeración en el territorio; iii) identificar regiones prioritarias de atención para prevenir homicidios y desapariciones forzadas; y, iv) explorar la relación estadística a escala municipal entre homicidios y desapariciones forzadas con indicadores oficiales (o estimados a partir de fuentes oficiales) de marginación social, rezago social, pobreza y desigualdad. El periodo de análisis es de 2006 a 2017, con el fin de cubrir una década completa y prácticamente dos sexenios: desde la declaración de la "Guerra contra el Narco" hasta el año previo al proceso electoral del segundo sexenio. El análisis se hizo con métodos de estadística convencional y de estadística espacial con 99 por ciento de nivel de confianza.
\end{abstract}

Palabras clave: Homicidios, desapariciones forzadas, México, municipio, análisis espacial.

Abstract

The objectives of this work are i) unveil the dynamics of homicides and enforced disappearances in Mexico, its states and in the 2,458 municipalities of the country; ii) discover the spatial pattern of homicides and disappearances in the municipal scale of Mexico in terms of its intensity and agglomeration in the territory; iii) Identify priority regions of care to prevent homicides and forced disappearances; and, iv) Explore the statistical relationship at the municipal level between homicides and forced disappearances with official indicators (or estimated from official sources) of social marginalization, social backwardness, poverty, and inequality. The period of analysis was from 2006 to 2017, in order to cover a full decade and practically two six-year terms: from the declaration of the "War against Narco" until the year prior to the electoral process of the second presidential period. The analysis was done with conventional and spatial statistics methods with 99 per cent confidence level.

Keywords: Homicide, enforced disappearances, Mexico, municipality, spatial analysis. 


\section{INTRODUCCIÓN}

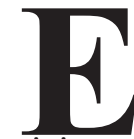

$\mathrm{n}$ años recientes México ha sufrido una profunda crisis de violencia vinculada al crimen organizado. Esta violencia es particularmente dolorosa en dos tipos de delitos: homicidios y desapariciones forzadas, que pueden monitorearse con cierta confianza porque tienen bajo subregistro (Pantoja, 2019). Las causas de esta crisis de violencia están a debate. En las elecciones presidenciales de 2018 llega al poder Andrés Manuel López Obrador, quien prometió, entre otras cosas, modificar la estrategia contra la violencia y complementarla con acciones que resolvieran, lo que llamó: "las causas" del problema. Estas causas, desde su punto de vista, son la pobreza, la desigualdad, y la marginación. (Presidencia de la República, 2019)

En este contexto, los objetivos de este trabajo son: i) develar la dinámica de los homicidios y las desapariciones forzadas en México, sus entidades federativas y los 2 mil 458 municipios del país; ii) descubrir el patrón espacial de los homicidios y desapariciones en la escala municipal de México en términos de su intensidad en el territorio; iii) Identificar regiones prioritarias de atención para prevenir homicidios y desapariciones forzadas; $\mathrm{y}$ iv) Explorar la relación estadística a escala municipal entre homicidios y desapariciones forzadas con indicadores oficiales (o estimados a partir de fuentes oficiales) de marginación social, rezago social, pobreza y desigualdad. El periodo de análisis fue de 2006 a 2017, con el fin de cubrir una década completa y prácticamente dos sexenios (los de los expresidentes Felipe Calderón y Enrique Peña Nieto): desde la declaración de la "Guerra contra el Narco" hasta el año previo al proceso electoral del segundo sexenio. El análisis se hizo con métodos de estadística convencional y de estadística espacial con 99 por ciento y 95 por ciento de nivel de confianza.

A parecer no existe ningún trabajo de escala nacional que explore homicidios y desapariciones forzadas, aplicando técnicas de análisis espacial, y que incluya todos los municipios del país. Este trabajo contribuye a llenar este hueco en la literatura especializada sobre uno de los mayores problemas del México contemporáneo.

La estrategia de presentación sigue puntualmente los objetivos del trabajo. Primero se hace una breve síntesis del estado del conocimiento sobre nuestro tema de investigación en México y en Latinoamérica (por su cercanía socioespacial con México), para contextualizar empíricamente el análisis, especialmente en el tema de las causas de la violencia extrema. En la Sección 2, se especifica la metodología que soporta el artículo. 
Posteriormente inicia el trabajo empírico. En la Sección 3 se muestra la magnitud y dinámica de los homicidios y las desapariciones forzadas en México, sus entidades federativas y los dos mil 458 municipios del país, identificando algunos puntos clave de la evolución del fenómeno. En la Sección 4 se revela el patrón espacial de los homicidios y desapariciones en la escala municipal de México. Específicamente, se responde la pregunta: ¿La violencia extrema se distribuye aleatoriamente en el territorio o existen clústers municipales de violencia estadísticamente significativos? La respuesta a esta cuestión ofrece bases para, en la Sección 5, identificar regiones prioritarias de atención que pueden ser útiles para prevenir la incidencia de violencia extrema. Para cumplir el último objetivo de la investigación sólo resta plantear la pregunta: ¿La violencia extrema registrada en los municipios se relaciona estadísticamente con la adversidad social municipal? Por ello se examina la relación estadística a escala municipal de la incidencia de violencia extrema y varios indicadores de adversidad social (marginación, rezago, pobreza, desigualdad). Finalmente, en la Sección 6 , se sintetizan los hallazgos y aportaciones del trabajo, que cierra con un listado de la bibliografía consultada.

\section{VIOLENCIA Y SOCIEDAD}

La violencia extrema, particularmente homicidios y desapariciones forzadas, ha sido de interés de diferentes áreas de la ciencia y por ello los enfoques son diversos. Naturalmente, en los países donde estos delitos son un problema mayor (e.g. Colombia) es donde se ha analizado más el tema. Vale la pena rescatar las principales lecciones que reporta la literatura más cercana a nuestro país (e.g. la Latinoamericana, especialmente la colombiana y la mexicana), para apoyar nuestro trabajo.

\section{Revisión de la literatura Latinoamericana}

En Colombia el homicidio fue en alguna época la primera causa de muerte, afectando mayormente a los hombres y mujeres entre 15 y 45 años de edad (Rodríguez, 2005). La incidencia de homicidios era tan alta que impactó negativamente la esperanza de vida de la población en su conjunto. La violencia no sólo afecta a la demografía y la atmósfera social, también afecta la economía (Carranza et al., 2011; Concha, 2002). Se ha estimado que los homicidios impactan negativamente al PIB de Sudamérica en 14 por ciento (Carrión, 2005).

Economistas y demógrafos han intentado predecir estadísticamente la cantidad de muertes violentas en Bogotá (Sánchez et al., 2005) o la 
asociación entre el incremento de la población joven y el incremento de homicidios (Bonilla, 2010). Algunos sociólogos utilizan categorías como la desorganización social, para comparar la incidencia de homicidios en Colombia con Estados Unidos y teorizar al respecto (Escobar, 2012) o construir escenarios de la violencia homicida en ciudades como Medellín (Cardona et al., 2005; Franco et al., 2012). Incluso, desde la siquiatría se han buscado factores de riesgo a la actividad delictiva (Acero et al., 2007; Rodríguez Gázquez, 2008). Otros estudios revelan que los homicidios se relacionan estrechamente con el conflicto armado que desde hace medio siglo azota a Colombia (Echandia, 2001) y con la pobreza y adversidad social de muchas de sus regiones.

También se han descubierto en Colombia variaciones estacionales de la violencia (Rodríguez, 2008). Lo mismo en Costa Rica, donde Sáenz (2006) encuentra que hay una asociación entre homicidios, masculinidad y fines de semana. También se reporta la relación de la violencia con pobreza, desempleo, consumo de drogas y tenencia de armas (Mata y Solano, 2006). Por su parte, Gaborit (2005) encuentra para Honduras, El Salvador y Guatemala tasas de homicidios crecientes, pero a velocidades y ritmos más acelerados.

En Venezuela y Argentina, el fenómeno del homicidio también es uno de los temas de atención prioritaria. Álvarez (2010) encuentra que hay determinantes asociados a la crisis de partidos en Venezuela, que se vinculan con el alto crecimiento de homicidios. Spinelli et al. (2008) analizan el papel de los factores macroeconómicos en Argentina sobre el incremento de la tasa de homicidios. Zunino et al. (2006), revelan que las fuentes estadísticas de mortalidad de Buenos Aires enmascaran el fenómeno de la violencia cuando se trata de homicidio por arma de fuego.

En Colombia, el fenómeno de las desapariciones forzadas también se ha presentado recurrentemente (Rojas, 2013). En Latinoamérica se ha acuñado, desde las ciencias forenses, la categoría de arqueología del terror para referirse a las desapariciones forzadas, y se busca dimensionar las consecuencias sociales de este fenómeno en Argentina, Guatemala y, sobre todo, en México (Huffschmid, 2015).

También existen reflexiones y teorizaciones que buscan esclarecer el fenómeno de los homicidios y las desapariciones forzadas en el conjunto de América Latina, o en algunas de sus regiones (Buvinic et al., 2005; Salama, 2008; 2013). Briceño-León (2008; 2012) relaciona los homicidios en toda América Latina con seis variables: pobreza, desigualdad, desempleo, riqueza nacional, desarrollo humano y gobierno de la ley. Algunos pro- 
ponen que en Latinoamérica la pobreza no es la causa directa del crimen, pero sí influye de manera indirecta, ya que se asocia a la exposición a la violencia en la adolescencia, la experiencia cotidiana de estrés, conflicto y la desesperanza de estar excluido o marginado de las oportunidades de progreso: la adversidad social (Vázquez, 2001).

Otras reflexiones sociológicas sugerentes en Latinoamérica ubican el problema de los homicidios como una forma de estigmatizar a los diferentes, o en su caso a los pobres, con lo que los prejuicios sociales se agudizan o consolidan (Castellano y Castellano, 2012). También hay quienes ven en el nuevo estilo de vida urbano, incluyendo las nuevas tecnologías y los medios masivos de comunicación, condicionantes del crecimiento de los homicidios en América Latina (Briceño-León, 2002), y otros reflexionan sobre la visión que, desde el exterior, se ha generado de esta problemática en México (Bergman, 2012).

Para el caso particular de México, Hernández y Narro (2010) al igual que González-Pérez et al. (2012) analizan estadísticamente el crecimiento de homicidios en el país, y descubren que desde 2008 hay un crecimiento significativo, sobre todo en algunos estados fronterizos donde, pocos años después, se agudizaría la ocurrencia de este delito. Para el grupo de edad de 10 a 19 años, González-Pérez et al. (2009) exploran las tasas de homicidios y encuentran que son superiores a las que se registran en muchos países industrializados (e.g. UK), aunque menores a las de varios países del continente americano (e.g. Brasil, USA, Puerto Rico), donde el factor de la presencia del narcotráfico juega un papel clave por el uso de las armas de fuego. Meneses-Reyes y Fondevilla (2012) y Arroyo (2001) analizan este fenómeno en la Ciudad de México. Varios trabajos han develado que la confianza y solidez de las instituciones también son relevantes (Monárrez y García, 2008), así como la visión que tienen los gobiernos de sus instituciones (Gutiérrez et al., 2010).

Para el caso de las desapariciones forzadas, hay reflexiones de este fenómeno en México desde la llamada guerra sucia en los años setenta (Mendoza, 2015), las consecuencias que enfrentan las familias cuando uno de sus miembros es víctima de este tipo de violencia o las respuestas ciudadanas ante estos actos de barbarie (Morbiato, 2017; Cervantes, 2015; Villarreal, 2014). También hay reflexiones destacables desde distintas ópticas que buscan contextualizar y explicar los orígenes del fenómeno de la desaparición forzada en función del clima de violencia política, autoritarismo gubernamental, impunidad y delincuencia (Reveles, 2015; Robledo, 2016; y Pereyra, 2015) 
Para este trabajo son particularmente notables los textos de Vilalta (2010; 2013), que develan la dimensión espacial del crimen en la zona metropolitana de la Ciudad de México y modelan indicadores de crimen (Vilalta y Fondevila, 2019). Vilalta et al. (2016; 2016b), Vilalta y Muggah (2016) buscan explicar los delitos violentos en algunas ciudades de México, Costa Rica y Chile, utilizando técnicas de análisis espacial.

Como puede observarse, existen diversos trabajos latinoamericanos que abordan la problemática de los homicidios, pero son muchos menos los que estudian las desapariciones forzadas, que es otro crimen de violencia extrema. Por otro lado, la gran mayoría de los trabajos que reporta la literatura de nuestro subcontinente son reflexiones $\mathrm{y} / \mathrm{o}$ estudios basados solo en estadística No-espacial, con notables excepciones (Vilalta, 2010, 2013; Gasca y Flores, 2017; Fuentes y Sánchez 2015 y algunos otros). Los pocos trabajos que utilizan el análisis espacial para abordar el fenómeno de los homicidios dejan fuera las desapariciones forzadas y no cubren todo un país a nivel de desagregación municipal. Trabajos a escala nacional para México, con técnicas de análisis espacial y que consideren todos los municipios del país son, a la fecha, inexistentes (al menos no se conoce ninguno). Este trabajo contribuye a llenar este hueco en el estado del conocimiento de la violencia extrema en México.

\section{Metodología}

\section{Fuentes de información}

Se consideraron los homicidios reportados por el Instituto Nacional de Estadística Geografía e Informática (INEGI) y el Secretariado Ejecutivo del Sistema Nacional de Seguridad Pública (SESNSP) de 1990 a 2017. Dichos eventos son

los registrados en las averiguaciones previas o carpetas de investigación iniciadas, y que son reportados por las Procuradurías Generales de Justicia y Fiscalías Generales de las entidades federativas, en el caso de los delitos del fuero común, y por la Fiscalía General de la República, en el caso de los delitos del fuero federal (SESNSP, 2019a).

Las desapariciones forzadas corresponden al Registro Nacional de Datos de Personas Extraviadas o Desaparecidas (RNPED) dependiente del SESNSP, y están referidas a "datos de personas no localizadas obtenidos a partir de las denuncias presentadas ante la autoridad ministerial correspondiente" (SESNSP, 2019b). Se excluyeron los casos de homicidios y 
desapariciones que no se encontraban referenciados a municipios. La base de datos de desaparecidos del SESNSP, en su forma original, no está referida a las claves municipales del INEGI, sino al nombre de cada municipio. Para realizar los análisis estadísticos se tuvo que asignar las claves municipales del INEGI a la base del SESNSP, lo que implicó un arduo trabajo, ya que hay muchos municipios que tienen el mismo nombre en diferentes estados del país, por lo que fue preciso revisar cada caso y asignar la clave municipal correspondiente. La base de datos cartográfica procede del Marco Geoestadístico del INEGI (2016).

\section{Indicadores}

Los indicadores que se obtuvieron fueron: número de homicidios de todo tipo, número de desapariciones forzadas, número de víctimas de violencia letal (resultado de sumar los dos indicadores anteriores), tasas por cada 100 mil habitantes de homicidios, desapariciones y víctimas de la violencia letal. El análisis por números absolutos y por tasas muestra dos caras diferentes pero complementarias de la violencia extrema. Sería equivocado concentrarnos sólo en los números absolutos o en las tasas por 100 mil habitantes. El impacto social de los números absolutos de la violencia extrema es muy inquietante para la población, especialmente en las zonas de mayor densidad, mientras que las tasas permiten hacer comparaciones entre unidades espaciales (e.g. países, estados, municipios) evitando el efecto distorsionante del tamaño de la población. Los indicadores de adversidad social que se utilizaron fueron: Índice de Marginación (CONAPO, 2010); Índice de Rezago Social y Medición de la Pobreza (CONEVAL, 2010; 2018); y el Coeficiente de Gini de distribución del ingreso municipal.

Las categorías por tipo de violencia extrema se delimitaron mediante el método de Dalenius y Hodges, también conocido como Estratificación Óptima. El procedimiento seguido fue: i) se calcula el número de intervalos adecuados a dividir el índice, a través del entero resultante del logaritmo base 10 del número total de casos ii) el índice se divide en el número de intervalos resultante iii) se calcula el número de casos que cae dentro de cada intervalo iv) se obtiene la raíz cuadrada del número de casos en cada intervalo y se acumula consecutivamente v) la raíz cuadrada acumulada del último intervalo, se divide entre el número de estratos a obtener. El primer estrato es la cantidad obtenida, el segundo el doble, el tercero el triple y así hasta el último estrato vi) el límite máximo de cada estrato corresponderá al valor más cercano en la columna de raíces cuadradas acumuladas, 
y su respectivo rango en los intervalos del índice vii) se asigna el estrato correspondiente a cada uno de los casos en su respectivo estrato.

\section{Correlaciones}

Para probar si la adversidad social está asociada al lugar donde se registran judicialmente los eventos de la violencia extrema, correlacionamos nuestros seis indicadores de violencia que obran en averiguaciones previas o carpetas de investigación iniciadas, con los indicadores de adversidad social antes señalados. Estimamos correlaciones convencionales no-paramétricas. Suponemos que la gran mayoría de los eventos de violencia extrema se registran judicialmente en el municipio donde ocurrió el delito. Este supuesto también lo asume el SESNSP, responsable de las estadísticas oficiales sobre incidencia delictiva (SESNSP, 2019a).

\section{Patrón espacial de la violencia}

Con el fin de identificar el patrón espacial de la violencia extrema se calcularon los índices de autocorrelación de Moran, tanto Globales como Locales, para los seis indicadores de violencia considerados. Los índices Globales nos permitieron mostrar el patrón espacial de la violencia a escala del país (e.g. aglomerado o disperso) y los índices Locales nos revelaron clusters de municipios en el territorio, de acuerdo a sus indicadores de violencia extrema. El Índice de Autocorrelación Global de Moran se calcula de la siguiente manera:

$$
I=\frac{n \sum_{i=1}^{n} \sum_{i=1}^{n} w_{i j}\left(y_{i}-y\right)\left(y_{j}-y\right)}{\left(\sum_{i=1}^{n}\left(y_{i}-y\right)^{2}\right)\left(\sum_{i \neq 1} \sum w_{i j}\right)}
$$

Donde:

$\mathrm{y}_{\mathrm{i}}=$ valor de la variable o atributo en cada unidad espacial analizada "i".

$\mathrm{y}_{\mathrm{j}}=$ valor de la variable o atributo en cada unidad espacial vecina “ $\mathrm{j}$ ”.

$\mathrm{w}_{\mathrm{ij}}=$ proximidad entre las unidades espaciales " $\mathrm{i}$ " $\mathrm{y}$ " $\mathrm{j}$ " (llamada también "matriz de pesos espaciales") y que puede ser estimada a partir de la localización absoluta (medida mediante distancias entre unidades espaciales) o relativa (establecida a partir de criterios de vecindad).

$\mathrm{n}=$ número de unidades espaciales. 
Geografía del terror: homicidios y desapariciones forzadas en los municipios de México 2006-2017 / E. CADENA y C. GARROCHO

\section{Regiones prioritarias de atención}

Para identificar las regiones prioritarias de atención para prevenir la violencia extrema utilizamos el método de Jenks, que permite combinar números absolutos y tasas para resolver problemas taxonómicos (Wang et al., 2019). Este método cumple la doble condición de agrupar los datos en conjuntos homogéneos y maximiza las diferencias entre ellos. Se buscan, a través de software, los puntos de ruptura naturales existentes y se fijan como los límites de cada clase. Se basa en la prueba de la bondad del ajuste (Goodness of Variance Fit o GVF), y es un proceso iterativo que calcula la media de cada clase con las respectivas varianzas, y traslada observaciones entre las distintas clases hasta obtener el valor máximo del GVF (ESRI, 2019).

\section{Software}

Se utilizaron IBM SPSS 24, ESRI ArcMap 10.2 y Geoda 1.8. Se contó con el apoyo de la Estación de Inteligencia Territorial: CHRISTALLER ${ }^{\circledR}$ de El Colegio Mexiquense (Chávez-Soto y Garrocho, 2018).

\section{Magnitud y dinÁMiCa de la ViolenCia EXTREMa}

\section{La escala nacional}

De 1990 a 2017 hay registrados, por municipio, 455 mil 874 homicidios y 31 mil 54 desapariciones forzadas. Es decir, casi medio millón (486 mil 928) de víctimas de estas formas atroces de violencia en poco más de un cuarto de siglo. Es preciso señalar que la naturaleza de estos dos fenómenos tiene una muy alta proporción en su denuncia ante las instancias oficiales. No obstante, sí existen casos donde no se registra el municipio de ocurrencia (Pantoja, 2019).

Para entender la dinámica de los homicidios se revisaron los datos desde 1990. Los homicidios registrados ese año fueron 14 mil 349. En 1992 se alcanzó un pico de 16 mil 409, para de ahí registrar una tendencia descendente hasta 2004 (Figura 1). A partir de ese año se registró un repunte hasta 2006 y en 2007 su incidencia descendió hasta ocho mil 845, situación muy similar a la de 2004. Se puede decir que la estrategia del expresidente Calderón funcionó (relativamente) durante ese primer año de gobierno: no sólo detuvo la tendencia al alza de los homicidios, sino que la bajó a los niveles de tres años antes. No obstante, ese no fue el principio de la recuperación de la paz, sino el inicio del horror de la violencia extrema. A partir 
de 2008 los homicidios se elevaron explosivamente y rompieron la barrera de los 31 mil en 2011. Calderón logró bajar ligeramente los homicidios en 2012 (su último año de gobierno y año de elecciones presidenciales) a los niveles de 2010: alrededor de 28 mil en el año. Logro famélico. Al final de 2012 toma el poder Enrique Peña Nieto. El nuevo gobierno federal bajó los homicidios durante 2013 y 2014, año en que se colocaron debajo de la cota de los 20 mil, pero a partir de ahí la estrategia de Peña se agotó y comenzó un alza sistemática hasta acercarse a los 32 mil homicidios en 2017 que rompió todos los récords históricos (Figura 1).

En el caso de las desapariciones forzadas, los registros, con un solo caso, iniciaron en 1992. De esa fecha hasta 2009 se incrementaron notablemente a mil 349 desapariciones, subieron a más de tres mil el año siguiente, y a cuatro mil en 2011. Todo el sexenio de Calderón aumentaron las desapariciones forzadas, excepto en 2012, que fue año de elecciones presidenciales (siempre años atípicos en México). Con la entrada del gobierno de Peña Nieto las desapariciones recuperaron su tendencia al alza. Descendieron ligeramente en 2015 (a los niveles de 2013), pero en 2016 alcanzaron su punto más álgido de los dos sexenios aquí analizados: más de cuatro mil 600 desapariciones forzadas. No obstante, en 2017 (año previo a las elecciones) los casos descendieron notablemente a alrededor de un mil 500, nivel similar al de 2009 (Figura 1).

Sumando homicidios y desapariciones forzadas, las cifras inician en 14 mil 349 en 1990, dos años después saltan a 16 mil 410, para descender paulatinamente hasta nueve mil 321 en 2004. De este último año hasta 2011 se triplicaron los homicidios y desapariciones forzadas hasta llegar a 30 mil 852, descendieron a 23 mil 975 en 2014 y se elevaron abruptamente hasta romper todas las marcas anteriores: 32 mil 417 en 2017 (Figura 1).

Analizado las tasas de incidencia de homicidios por 100 mil habitantes (a escala nacional), se encuentra que desde 1992 a 2005 la tendencia era descendente: de 5.8 a 2.4 (Figura 2). En 2006 se registra un repunte moderado que se mantiene prácticamente igual en 2007 (recordar que la "Guerra contra el Narco" inicia el 11 diciembre de 2006 con el Operativo Michoacán). Sin embargo, en 2008 la estrategia de Calderón naufraga: la tasa de homicidios creció de manera explosiva hasta casi multiplicarse por ocho, alcanzando 18.8 homicidios por cada 100 mil habitantes. En los siguientes cuatro años la tasa descendió notablemente hasta llegar a seis por cada 100 mil en 2014 (ligeramente superior a la de 1992), pero repuntó en 2015 hasta llegar a 11.3 en 2017. 
Geografía del terror: homicidios y desapariciones forzadas en los municipios de México 2006-2017 / E. CADENA y C. GARROCHO

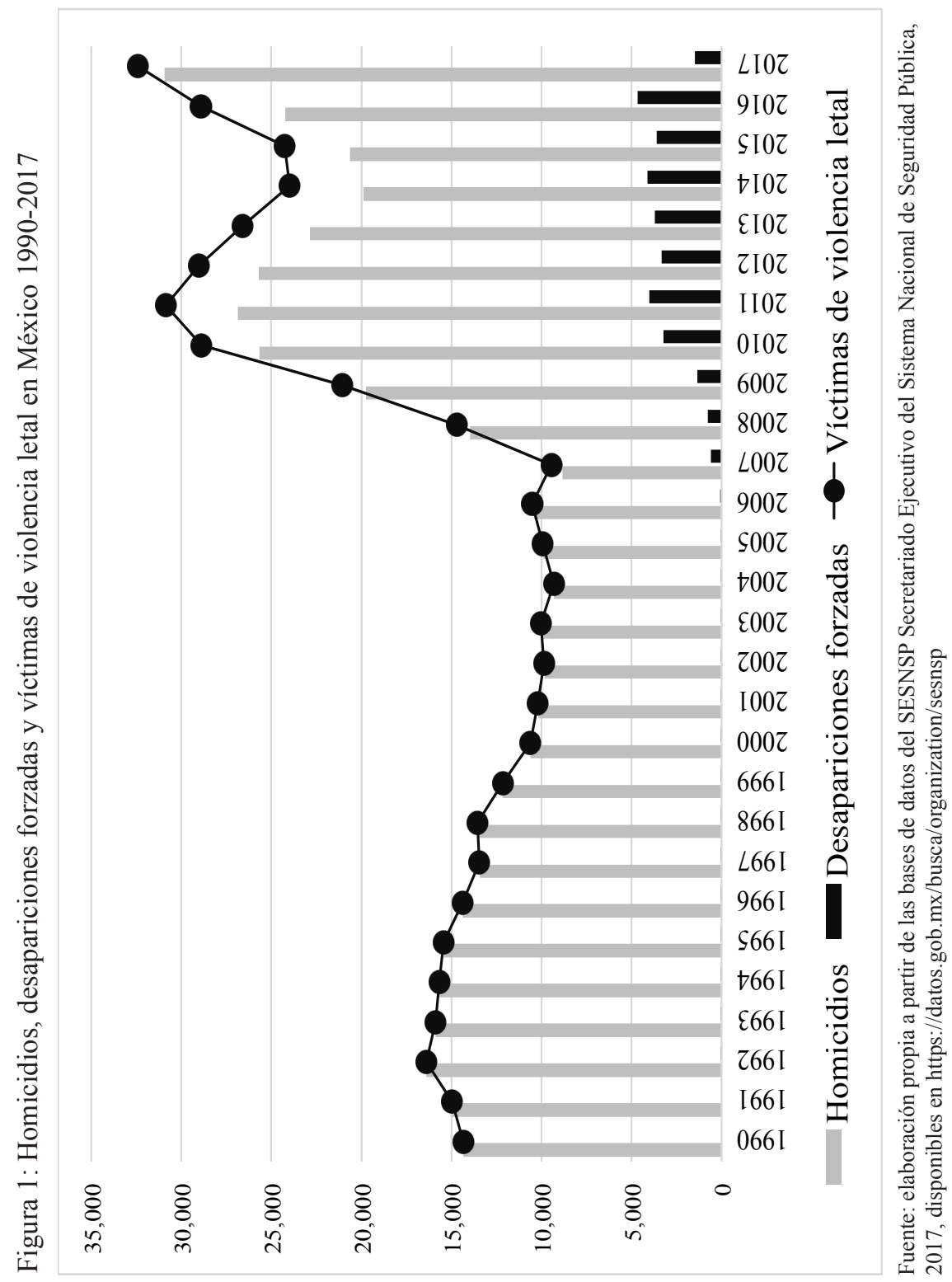


La tasa de desaparecidos evolucionó de una tasa de 0.3 en 2007 a una de 3.9 por cada 100 mil habitantes en 2011, lo que significa que se multiplicó por 13 en tan solo cuatro años, en plena "Guerra contra el Narco". De ahí, con sus alzas y sus bajas, descendió hasta 0.7 en 2017, durante el gobierno de Peña Nieto. Si se suman homicidios y desapariciones forzadas se observa una tendencia ascendente hasta 1992, un descenso hasta 2007, luego un aumento dramático hasta 19.4 por cada 100 mil habitantes en 2010, para descender hasta 5.9 en 2014 y duplicarse a 12 en 2017 (Figura 2).

De acuerdo con los datos, es correcto decir que, a partir del sexenio de Felipe Calderón (2006-2012), el número de homicidios y desapariciones forzadas en México se incrementó notablemente, pero también que siguió la misma tendencia durante el gobierno de Enrique Peña Nieto (20122017). Lo que no se puede deducir del análisis de los indicadores usados, es la razón por la cual un mayor combate al narcotráfico y la delincuencia organizada durante esos gobiernos desembocó en una mayor intensidad de la violencia, la agudización de otros delitos (como el robo y el secuestro), aparición masiva de nuevas formas de violencia (como la extorsión a establecimientos), y una extensión de la violencia a zonas donde anteriormente no se registraban situaciones de emergencia (ONCSJL, 2018).

Independientemente de ello, solo para el caso de homicidios, es necesario contextualizarlos con lo que ocurre en otras partes del mundo. En 2010, punto intermedio de nuestro periodo de estudio, México ocupaba el tercer lugar en cantidad de homicidios reportados por los gobiernos a la Organización de las Naciones Unidas ONU, solo superado por Brasil e India. Pero en términos de tasa por cada 100 mil habitantes, ocupaba el lugar 41, resaltando los casos de Honduras, cuya tasa era 4.5 veces más alta que la de México, El Salvador 3.6 veces, Jamaica 2.9, Venezuela 2.7, Belice y Guatemala con tasas 2.3 veces más elevadas. (UNODC, 2011) Cabe señalar que Honduras, El Salvador y Guatemala son los tres países centroamericanos que más migrantes expulsan a Estados Unidos y que transitan por México.

\section{La escala estatal}

Durante el periodo analizado hubo 249 mil 773 homicidios con registro municipal y 30 mil 903 desapariciones, lo que arroja un total de 280 mil 676 víctimas. Respecto de los homicidios, en tan solo cuatro entidades se concentró 38.6 por ciento del total, Chihuahua: 30 mil 455, Estado de México: 28 mil 576, Guerrero: 22 mil 369, y Sinaloa: 15 mil 166. 
Geografía del terror: homicidios y desapariciones forzadas en los municipios de México 2006-2017 / E. CADENA y C. GARROCHO

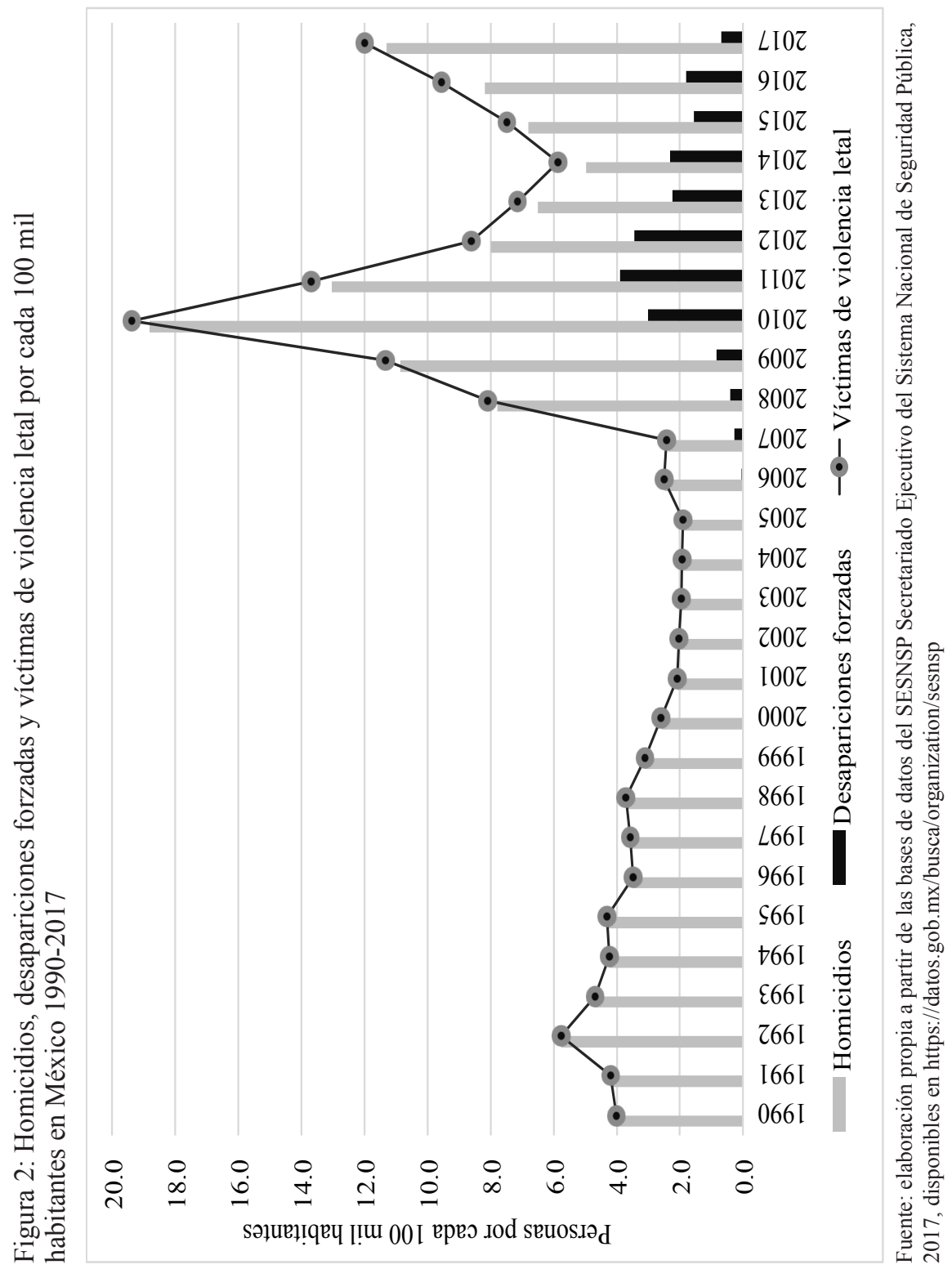


Si se agregan a estos cuatro estados Jalisco y la Ciudad de México, entonces, esas seis entidades concentraron prácticamente la mitad del total de homicidios del total nacional: 48.9 por ciento (pero 36.4 por ciento de la población del país). En contraste, en diez estados se localiza solo 10.2 por ciento del total de homicidios de todo el país (y 15.7 por ciento de la población de México), y fueron: Yucatán, Aguascalientes, Campeche, Tlaxcala, Querétaro, Baja California Sur, Quintana Roo, Hidalgo, Colima, Tabasco, Nayarit, Zacatecas y San Luis Potosí (Tabla 1).

Otro nivel de análisis necesario es por tasas por cada 100 mil habitantes. Si se acumulan los homicidios del periodo analizado, resalta que el primer lugar lo ocupó nuevamente Chihuahua con 894 homicidios acumulados por cada 100 mil habitantes en el periodo 2006-2017. Le siguen Guerrero, Sinaloa, Colima, Durango, Baja California, Nayarit, Morelos, Tamaulipas, Michoacán, Sonora, Baja California Sur, Zacatecas, y Oaxaca con tasas que van de 660 a 220 homicidios por cada 100 mil habitantes. En cambio, Campeche, Tlaxcala, Hidalgo, Querétaro, Aguascalientes y Yucatán tuvieron tasas de menos de 100 homicidios acumulados por cada 100 mil habitantes, resaltando el caso de Yucatán (que de nueva cuenta ocupó el último lugar en violencia extrema) que tiene una tasa de 29 homicidios por cada 100 mil (la tasa más baja del país) (Tabla 1 y Mapa 1). Incluso en materia de crimen, México es un país de contrastes.

Como era de esperarse, las entidades donde hay mayor cantidad de homicidios son los más poblados como el Estado de México y la Ciudad de México, que se ubican entre los más violentos en el imaginario colectivo. Sin embargo, cuando se analizan las tasas por 100 mil habitantes, aparecen en escena estados que se mencionan con menor frecuencia en los medios de comunicación y cuyas tasas son de las más elevadas del mundo. ${ }^{1}$

En el periodo analizado (2006-2017) se acumularon 30 mil 903 desapariciones, destacando el caso de Tamaulipas, que concentró 18.6 por ciento del total nacional. En solo siete estados se aglutinaron las dos terceras partes de las desapariciones en el país (66.1 por ciento, cuya población representa 35 por ciento del total nacional): Tamaulipas, 18.6 por ciento; Estado de México, 11.3 por ciento; Jalisco, 8.8 por ciento; Nuevo León, 8.1 por ciento; Sinaloa, 7.9 por ciento; Chihuahua, 6.3 por ciento; y Coahuila,

${ }^{1}$ En 2018 las tasas de homicidios por cada 100 mil habitantes más elevadas del país fueron: Colima (113) y Baja California Sur (91). Ni siquiera El Salvador, con una tasa de 83, la más elevada del mundo en 2016, igualó las cifras de estos estados de México (Banco Mundial: https://datos.bancomundial.org/indicador/vc.ihr.psrc.p5). En 2018 la tasa de homicidios por cien mil habitantes de Guerrero fue 71, Baja California: 60, Chihuahua: 59, tasas superiores a la de Honduras (57) que tuvo la segunda tasa de homicidios más elevada del mundo en 2016 (Banco Mundial, mismo enlace). 
5.1 por ciento (Tabla 1). En cambio, en 14 estados hubo menos de uno por ciento del total nacional de desapariciones forzadas en cada uno de ellos (a pesar de que representan 23.8 por ciento de la población total del país). Estos estados fueron: Colima, Morelos, Aguascalientes, Hidalgo, Oaxaca, San Luis Potosí, Tabasco, Yucatán, Chiapas, Quintana Roo, Campeche, Baja California Sur, Tlaxcala, y Nayarit (Tabla 1).

Como puede observarse, el fenómeno de las desapariciones forzadas ha sido más agudo en el norte de México y en el centro (en el Estado de México). En el primer caso son entidades importantes en la siembra y trasiego de drogas, y el caso de la segunda entidad se explica porque, junto con la Ciudad de México (con la cual se conurba) forma un mercado de más de 25 millones de habitantes muy rentable para el crimen organizado (e.g. consumo de drogas, trata de personas, pago de derecho de piso), que registra severos déficits de seguridad y en permanente disputa por diferentes grupos delincuenciales.

Visto por tasas, los estados que presentaron de 30 a 176 desapariciones acumuladas por cada 100 mil habitantes fueron Tamaulipas, Sinaloa, Coahuila, Chihuahua, Nuevo León, Sonora, Guerrero, Colima, Jalisco, y Zacatecas. Por el contrario, las 13 entidades donde hubo menos de diez desapariciones por cada 100 mil habitantes fueron Veracruz, Ciudad de México, Hidalgo, Campeche, Baja California Sur, Quintana Roo, Yucatán, San Luis Potosí, Oaxaca, Tabasco, Tlaxcala, Nayarit y Chiapas (Tabla 1 y Mapa 2).

Siete estados concentraron más de la mitad de las víctimas de homicidios y desapariciones forzadas (53.3 por ciento): Chihuahua, 11.5 por ciento; Estado de México, 11.4 por ciento; Guerrero, 8.5 por ciento; Sinaloa, 6.3 por ciento; Jalisco, 5.6 por ciento; Tamaulipas, 5.3 por ciento; y la Ciudad de México, 4.8 por ciento. En contraste, en nueve estados se concentraron menos de la veinteava parte del total de las víctimas (4.9 por ciento), en orden descendente: Tabasco, Hidalgo, Quintana Roo, Querétaro, Baja California Sur, Tlaxcala, Aguascalientes, Campeche, y Yucatán (Tabla 1).

Analizado por tasas, en ocho estados hubo más de 300 víctimas de violencia letal por cada 100 mil habitantes: Chihuahua, Guerrero, Sinaloa, Colima, Tamaulipas, Durango, Baja California, y Morelos. En la situación opuesta se encuentran seis entidades donde hay menos de 100 víctimas por cada 100 mil habitantes, Campeche, Querétaro, Tlaxcala, Hidalgo, Aguascalientes, y Yucatán (Tabla 1). 


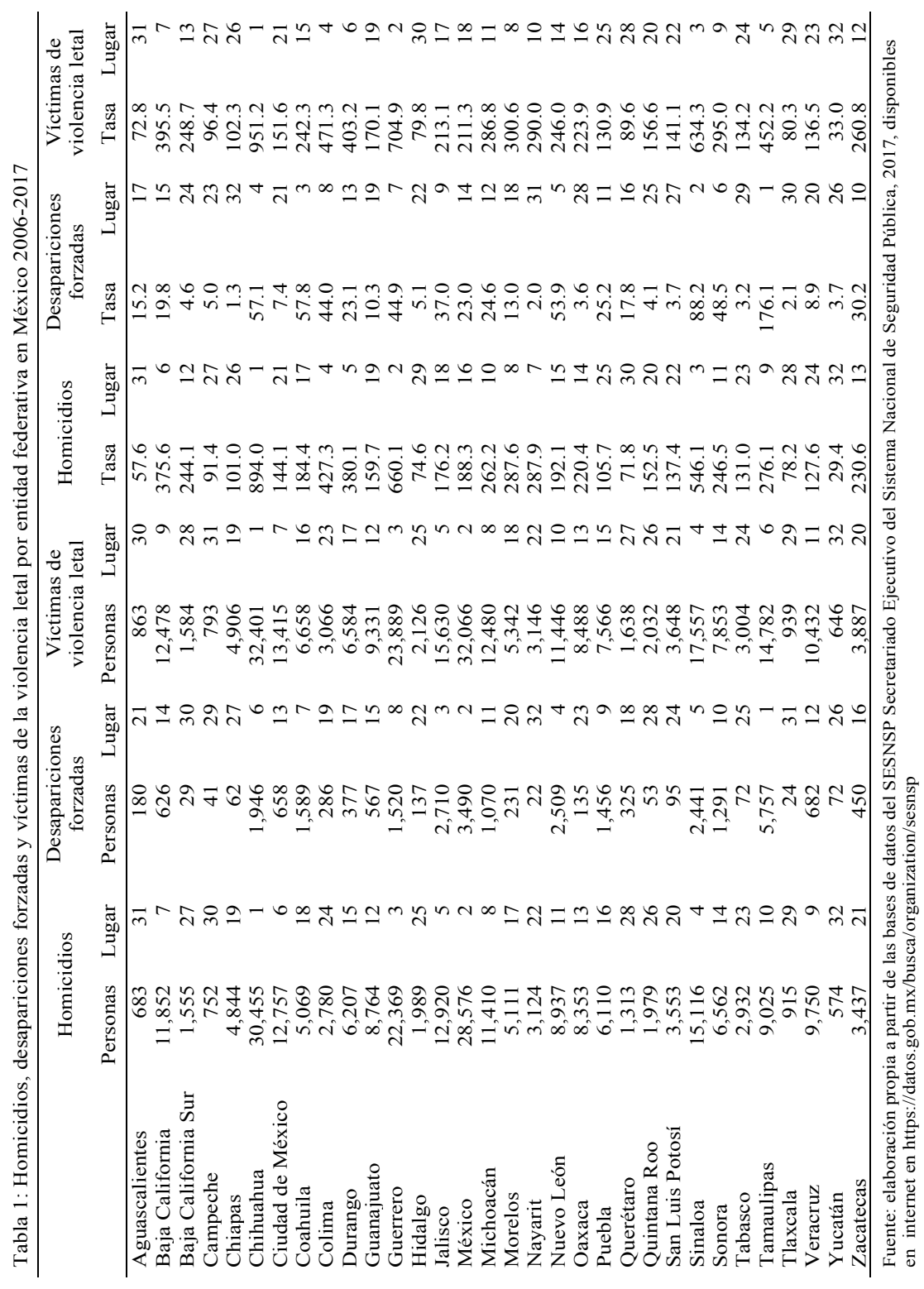


Geografía del terror: homicidios y desapariciones forzadas en los municipios de México 2006-2017 / E. CADENA y C. GARROCHO

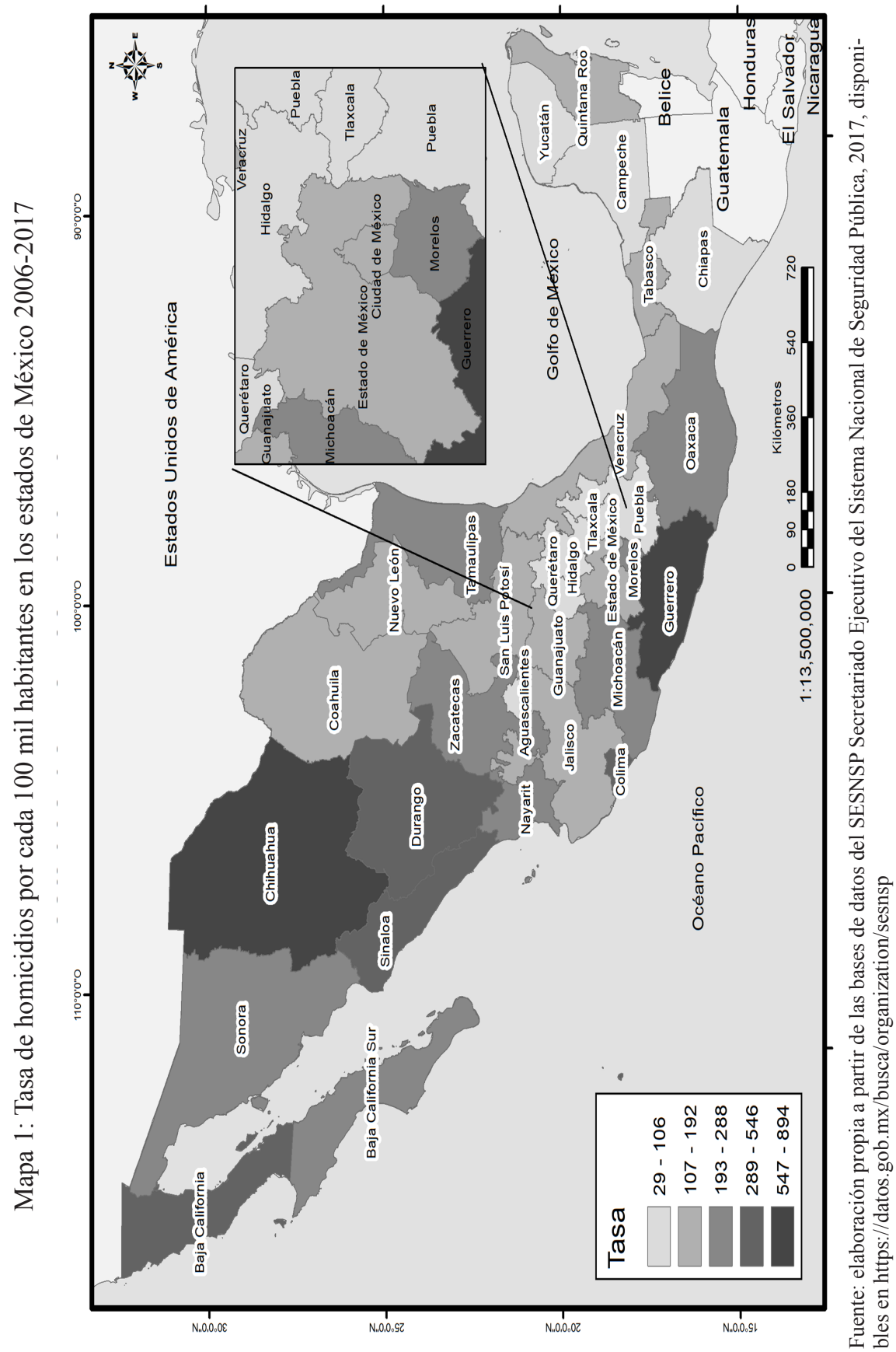




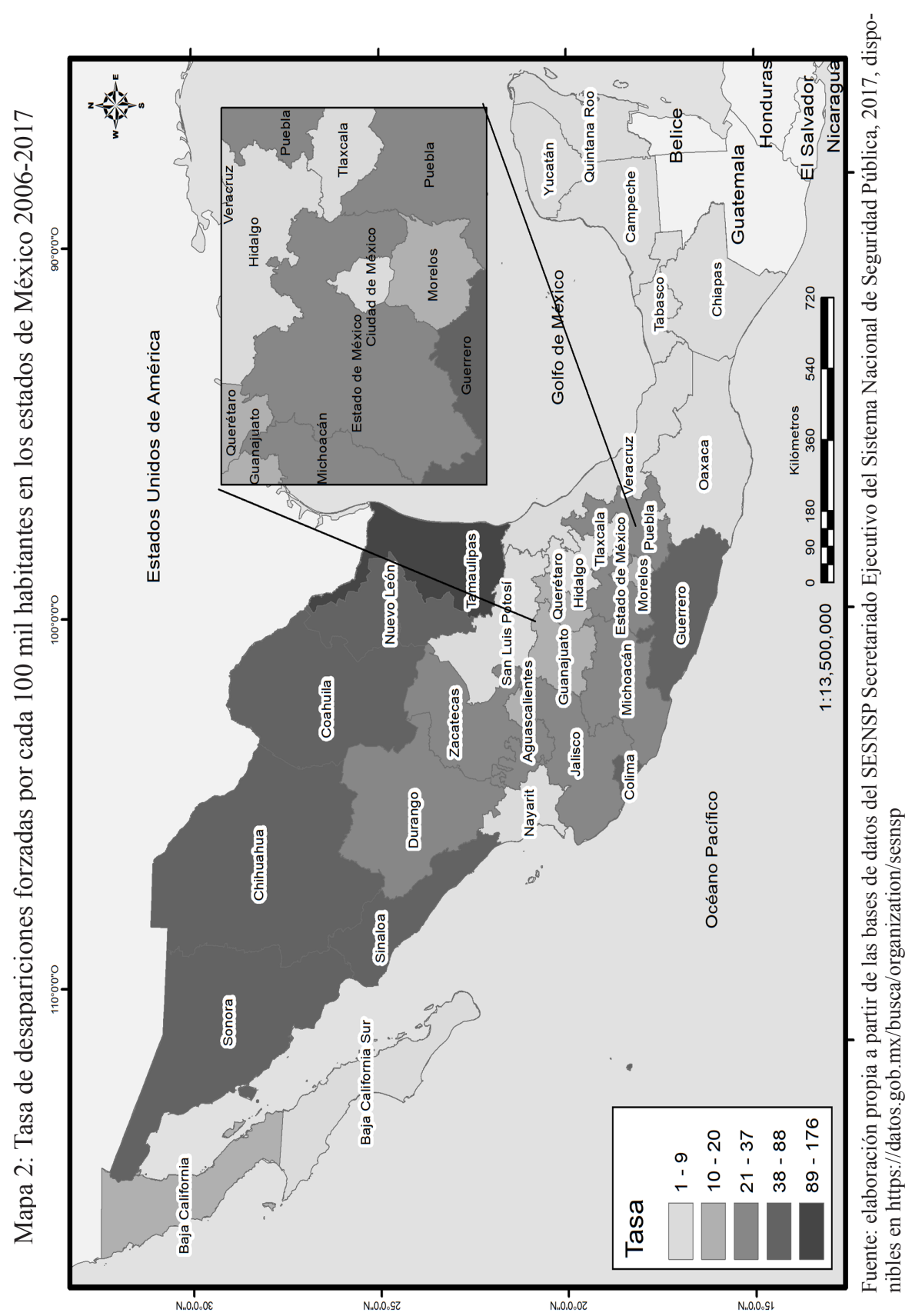


Así, Chihuahua fue el estado que ocupó, tanto en número como en tasa, el primer lugar en homicidios y víctimas de la violencia letal en el país, no así en desapariciones, rubro en el que ocupa los lugares seis y cuatro, en número y tasa, respectivamente. Por su parte, el Estado de México (el más poblado del país) ocupó el segundo lugar en número de homicidios, desapariciones y víctimas de la violencia letal, pero los lugares 16,14 y 18 en tasas de incidencia por 100 mil habitantes. Guerrero fue el número tres en cantidad de homicidios, ocho en desapariciones forzadas y tres en víctimas de la violencia letal; y por tasas ocupó los lugares dos, siete y dos. Sinaloa fue el número cinco en cantidad de homicidios, cinco en desapariciones y cuatro en víctimas de la violencia letal, pero en tasas sus lugares fueron tres, dos y tres. La capital del país, la Ciudad de México, ocupó el lugar seis en número de homicidios, 13 en desaparecidos y siete en víctimas de la violencia letal, pero por tasas, en los tres casos, fue el lugar 21. Es incorrecta la imagen colectiva de que la Ciudad de México y el Estado de México están entre las entidades más peligrosas del país.

\section{La escala municipal}

Analizados por cantidad, los homicidios se concentraron más en los municipios que corresponden a grandes ciudades o zonas metropolitanas de estados claramente vinculados con esta forma de violencia extrema, por su posición geográfica en el trasiego de drogas, por ser mercados de consumidores de suma importancia o sedes de cárteles en disputa. Los diez municipios líderes en homicidios en el periodo analizado, en orden descendente, fueron: Juárez (en Chihuahua) con 14 mil 403; Tijuana (Baja California), ocho mil 574; Acapulco (Guerrero), ocho mil 288; Culiacán (Sinaloa), cinco mil 866; Chihuahua (Chihuahua), cinco mil 555; Ecatepec (Estado de México), cuatro mil 721; Monterrey (Nuevo León), tres mil 287; Guadalajara (Jalisco), dos mil 862; Torreón (Coahuila), dos mil 750; e Iztapalapa (Ciudad de México), dos mil 567 (Tabla 2).

De los dos mil 458 municipios que hay en México, en 186 no se registró un solo homicidio de 2006 a 2017; en 122 se registró solo uno y en 140, dos. En la tercera parte de los municipios de México, 831, se registraron seis o menos homicidios en los once años del análisis.

Como se observa en el Mapa 3, fue en el noroeste, sur y centro del país donde se ubicaron los municipios donde hubo más homicidios. Destacan, en conjunto, la zona metropolitana de la Ciudad de México, la costa de Guerrero, y, particularmente, la zona fronteriza norte. 


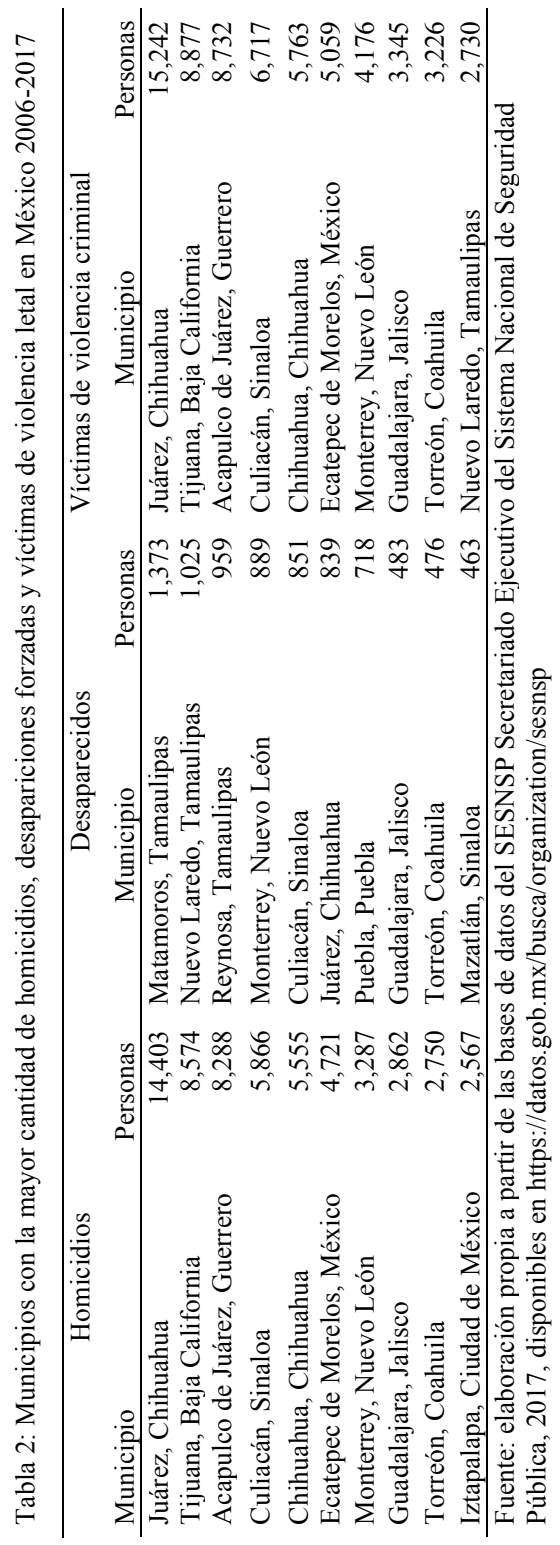


Geografía del terror: homicidios y desapariciones forzadas en los municipios de México 2006-2017 / E. CADENA y C. GARROCHO

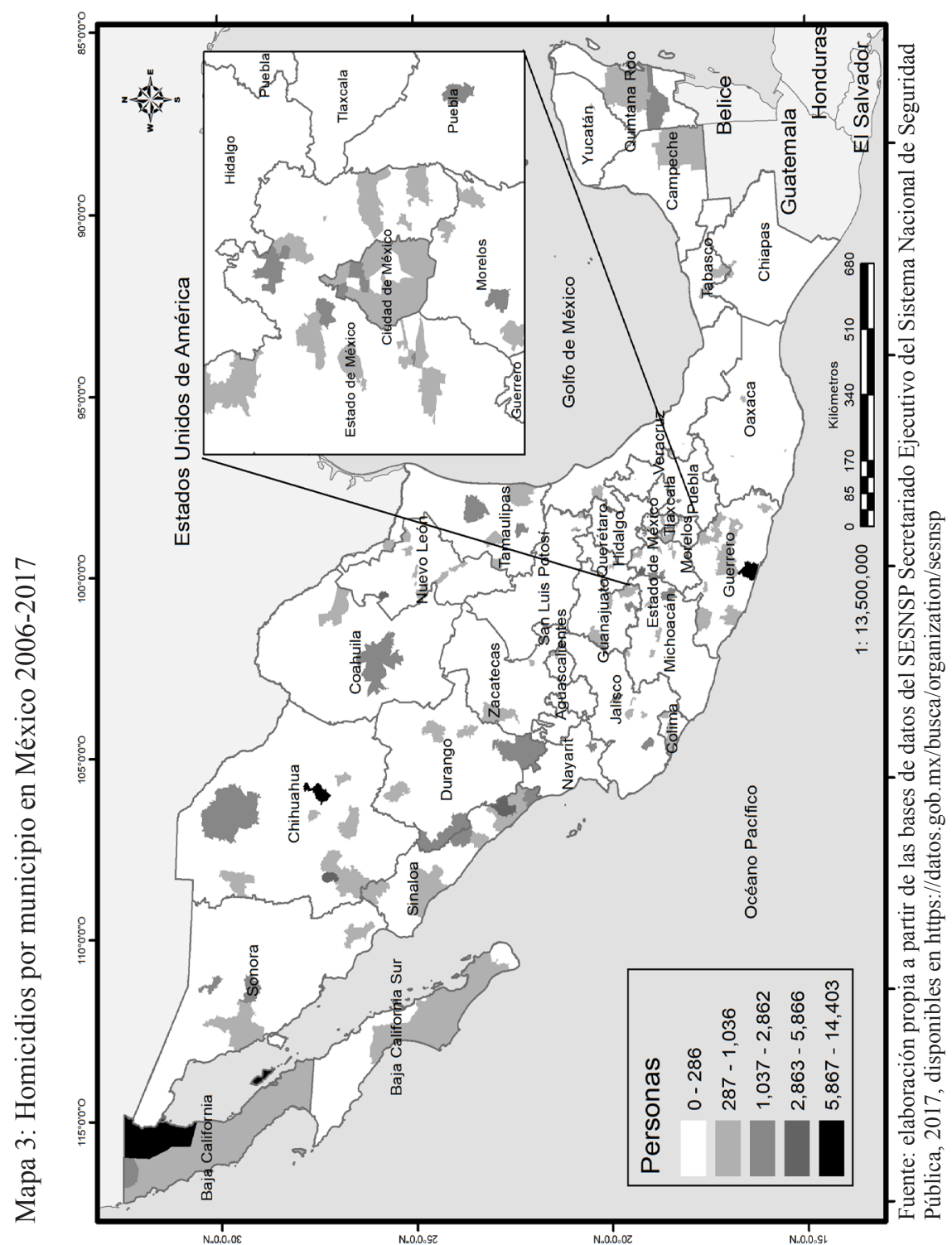


Medidos por tasas de homicidios por 100 mil habitantes, los diez municipios donde el fenómeno de los homicidios fue más intenso son: Vallecillo (Nuevo León), con tres mil 957 homicidios acumulados por cada 100 mil habitantes; Guadalupe (Chihuahua), tres mil 438; Praxedis G. Guerrero (Chihuahua), tres mil 42; Parás (Nuevo León), dos mil 611; Guadalupe y Calvo (Chihuahua), dos mil 523; General Treviño (Nuevo León), dos mil 506; Sáric (Sonora), dos mil 257; Tubutama (Sonora), dos mil 248; Uruachi (Chihuahua), dos mil 61; y Mier (Tamaulipas), dos mil 37. La inmensa mayoría de los mexicanos ni siquiera ha escuchado el nombre de muchos de estos municipios que son los diez más peligrosos de México. Muy pocos los podrían localizar en un mapa (ver Mapa 4).

Desde una perspectiva territorial, los municipios donde se localizan las tasas más altas de homicidios acumulados (entre un mil 601 y tres mil 957 homicidios por cada 100 mil habitantes) se concentraron en el noroeste, desde Nayarit hasta la frontera norte de Chihuahua, casi en la totalidad de Tamaulipas, Nuevo León, Michoacán, Guerrero y Morelos, así como amplias zonas de Oaxaca. Contra lo que muchos creen, en la zona metropolitana de la Ciudad de México (que incluye casi todos los municipios más poblados del Estado de México) son menos comunes los municipios que padecen violencia extrema (Ver Mapa 4).

Los municipios donde hubo mayor cantidad de desaparecidos forman un corredor que va desde Nayarit a Baja California, buena parte de Chihuahua y Guerrero, la zona metropolitana de la Ciudad de México, al igual que la parte norte de Tamaulipas, y algunas zonas de Guanajuato (Ver Mapa 5).

En desapariciones forzadas acumuladas, medidas por tasas, los diez municipios más peligrosos fueron Matamoros (Tamaulipas), un mil 373; Nuevo Laredo (Tamaulipas), un mil 25; Reynosa, (Tamaulipas), 959; Monterrey (Nuevo León), 889; Culiacán (Sinaloa), 851; Juárez (Chihuahua), 839; Puebla (Puebla), 718; Guadalajara (Jalisco), 483; Torreón (Coahuila), 476; y Mazatlán (Sinaloa), 463 (Tabla 2). En contraste, en más de la mitad de los municipios del país (un mil 374), no fue registrado un solo caso de desaparición forzada. Y en poco menos de la cuarta parte, 597, hubo de uno a cinco desaparecidos en los once años de referencia. En conjunto, en un mil 971 municipios, las cuatro quintas partes del total nacional, se registraron de cero a cinco desaparecidos durante el lapso referido. Al igual que los homicidios, las desapariciones forzadas no son un fenómeno generalizado en México, como sugieren las mediciones nacionales (e.g. las de los organismos internacionales) y en gran parte las estimaciones estatales. 
Geografía del terror: homicidios y desapariciones forzadas en los municipios de México 2006-2017 / E. CADENA y C. GARROCHO

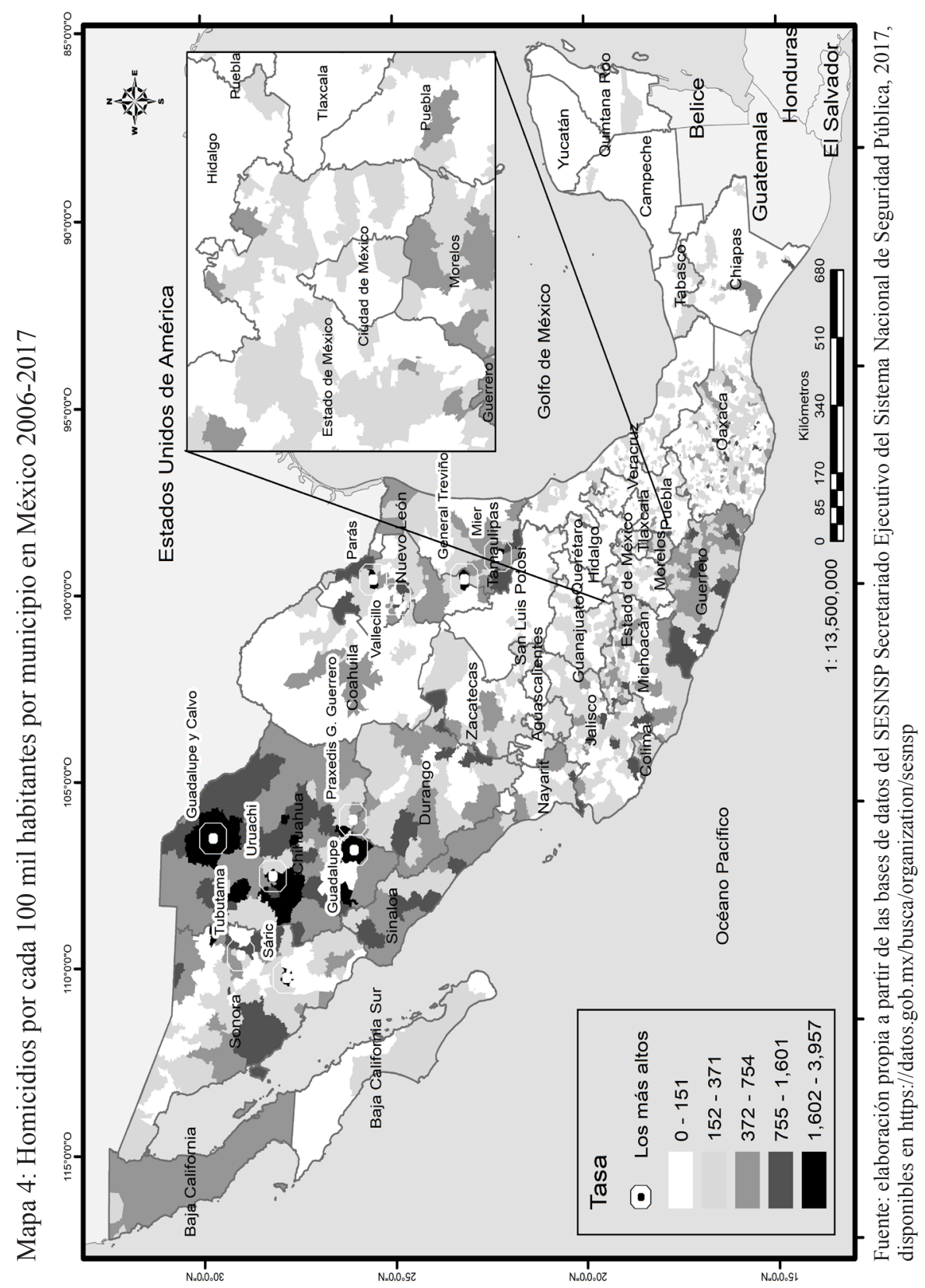




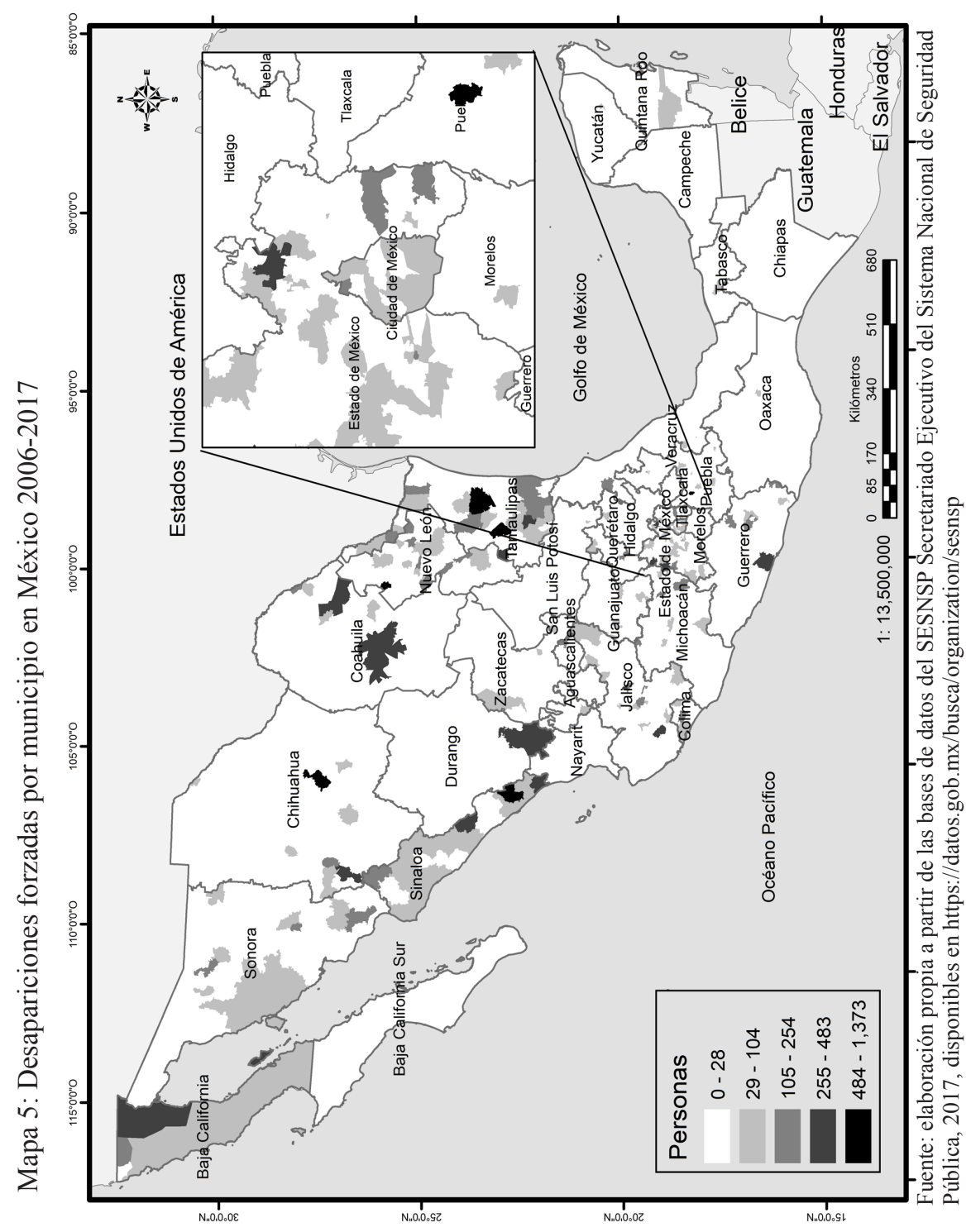


La ventaja de utilizar unidades espaciales micro (e.g. municipios) es que se devela la dimensión territorial de la violencia extrema a un nivel más realista y mucho más útil y relevante.

Cuando se analiza el fenómeno de las desapariciones a nivel municipal con tasas por 100 mil habitantes, cambia completamente la perspectiva: desaparecen las grandes ciudades (que son de las que más se ocupan los medios) y se revela que los municipios más peligrosos fueron los de menores tamaños y/o rurales. Los diez municipios donde el fenómeno de las desapariciones forzadas fue más intenso fueron: Mier (Tamaulipas), un mil 659 desapariciones por cada 100 mil habitantes; Guerrero (Tamaulipas), 692; Jiménez (Tamaulipas), 516; Tuxcacuesco (Jalisco), 496; Los Aldamas (Nuevo León), 437; El Plateado de Joaquín Amaro (Zacatecas), 435; Abasolo (Tamaulipas), 414; China (Nuevo León), 414; Sáric (Sonora), 370; y Miguel Alemán (Tamaulipas), 341. Es de señalar que los municipios de Mier y Sáric, también están entre los que tienen las tasas más altas de homicidios. Son municipios desconocidos para la gran mayoría de los mexicanos, pero el terror en el que deben vivir las personas en estos municipios es inimaginable (Ver Tabla 3).

Como se puede observar, las tasas de desaparecidos más altas se registraron en algunos de los municipios fronterizos con Estados Unidos, la mayor parte de los que pertenecen a Sinaloa, Tamaulipas y Nuevo León, así como en un corredor que va desde las costas de Colima y Jalisco, hacia Nayarit y Zacatecas. Le sigue el oriente del Estado de México, la mayor parte de la Ciudad de México y la parte costera y noreste de Guerrero, al igual que diversos municipios de Michoacán (Mapa 6). Esto lugares son claves para la salida de drogas a los Estados Unidos (e.g. Tamaulipas), la llegada de sustancias o drogas sintéticas de China (e.g. Acapulco), importantes mercados de consumo (e.g. Guadalajara, Monterrey, Ciudad de México, Acapulco: importante destino turístico nacional), puntos de producción de sustancias (e.g. diversos municipios de Sinaloa, Chihuahua, Durango) o territorios en disputa de cárteles (e.g. Jalisco, Nuevo León, Tamaulipas). (Ver Mapa 6) 


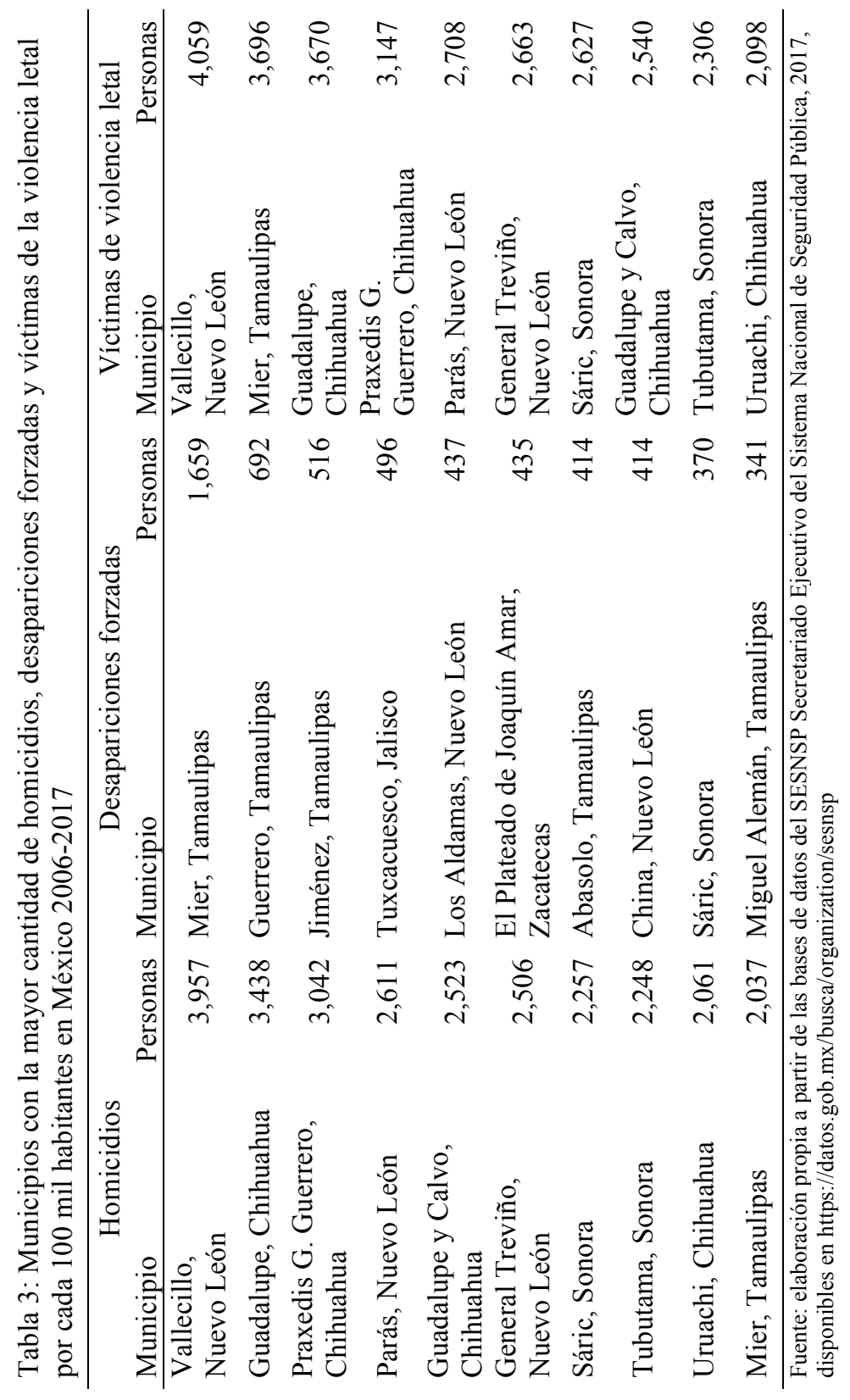


Geografía del terror: homicidios y desapariciones forzadas en los municipios de México 2006-2017 / E. CADENA y C. GARROCHO

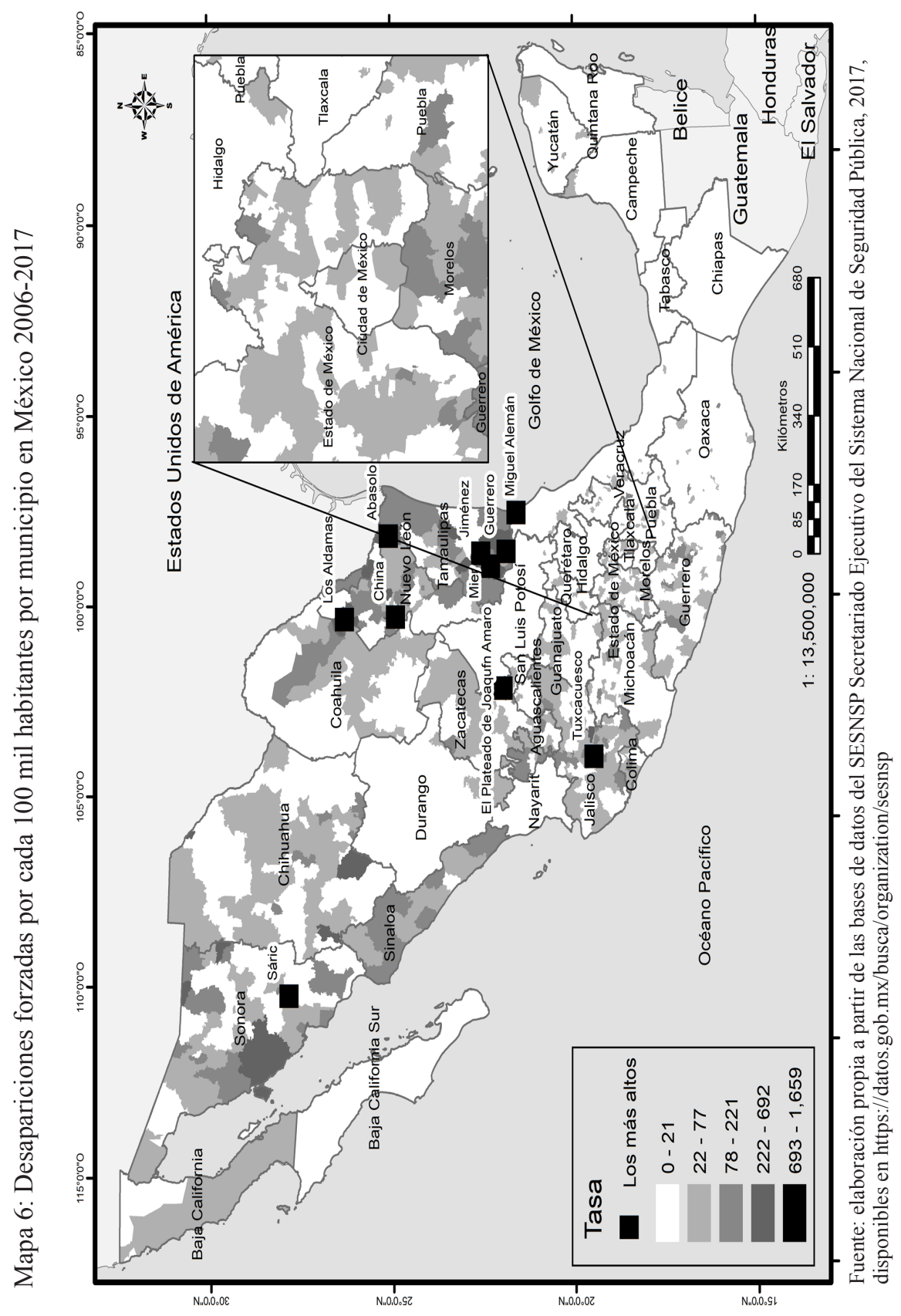


Si se agrupan los homicidios y las desapariciones forzadas bajo la categoría de víctimas de la violencia letal, los diez municipios líderes de 2006 a 2017 fueron Juárez (Chihuahua), 15 mil 242 víctimas; Tijuana (Baja California), ocho mil 877; Acapulco (Guerrero), ocho mil 732; Culiacán (Sinaloa), seis mil 717; Chihuahua (Chihuahua), cinco mil 763; Ecatepec (Estado de México) cinco mil 59; Monterrey (Nuevo León), cuatro mil 176; Guadalajara (Jalisco), tres mil 345; Torreón (Coahuila), tres mil 226; y Nuevo Laredo (Tamaulipas), dos mil 730. Todos estos municipios son estratégicos en el funcionamiento del mercado de narcóticos. Los municipios donde hubo mayor cantidad de víctimas de la violencia letal se localizan en la península de Baja California, en casi la totalidad de Sinaloa, gran parte de los estados de Sonora, Nayarit, Chihuahua, Tamaulipas, Durango y Zacatecas; amplias zonas de Guerrero y Quintana Roo, así como regiones completas del Estado de México, Guanajuato, Jalisco y la Ciudad de México (Mapa 7).

Los municipios donde hubo mayores tasas de víctimas de la violencia letal son Vallecillo, (Nuevo León), cuatro, mil 59 víctimas por cada 100 mil habitantes; Mier (Tamaulipas), tres mil 696; Guadalupe (Chihuahua), tres mil 670; Praxedis G. Guerrero (Chihuahua), tres mil 147; Parás (Nuevo León), dos mil 708; General Treviño (Nuevo León), dos mil 663; Sáric (Sonora), dos mil 627; Guadalupe y Calvo (Chihuahua), dos mil 540; Tubutama (Sonora), dos mil 306 y Uruachi (Chihuahua), dos mil 98 (Tabla 3). Municipios de terror cotidiano, desconocidos para la gran mayoría de los mexicanos y ausentes de los medios de comunicación (Mapa 8).

La mayor concentración de víctimas de la violencia letal por cada 100 mil habitantes forma un corredor de municipios muy amplio que abarca buena parte de los estados de Nayarit, Sinaloa, Sonora y Chihuahua. Otra región importante se observa en los estados de Jalisco, Colima, Michoacán, Guerrero y parte de Oaxaca, así como en la mayor parte de Tamaulipas y Nuevo León. En el centro, se ve cierta agrupación de municipios en Morelos, disminuyendo en la Ciudad de México, pero destacando ligeramente el oriente del Estado de México (Mapa 8). Los municipios de Mier, Guadalupe, Sáric, Uruachi, Tubutama, Praxedis G. Guerrero y General Treviño, son los lugares donde sus tasas son de las más altas del país en homicidios y/o desapariciones forzadas (Mapa 8). 
Geografía del terror: homicidios y desapariciones forzadas en los municipios de México 2006-2017 / E. CADENA y C. GARROCHO

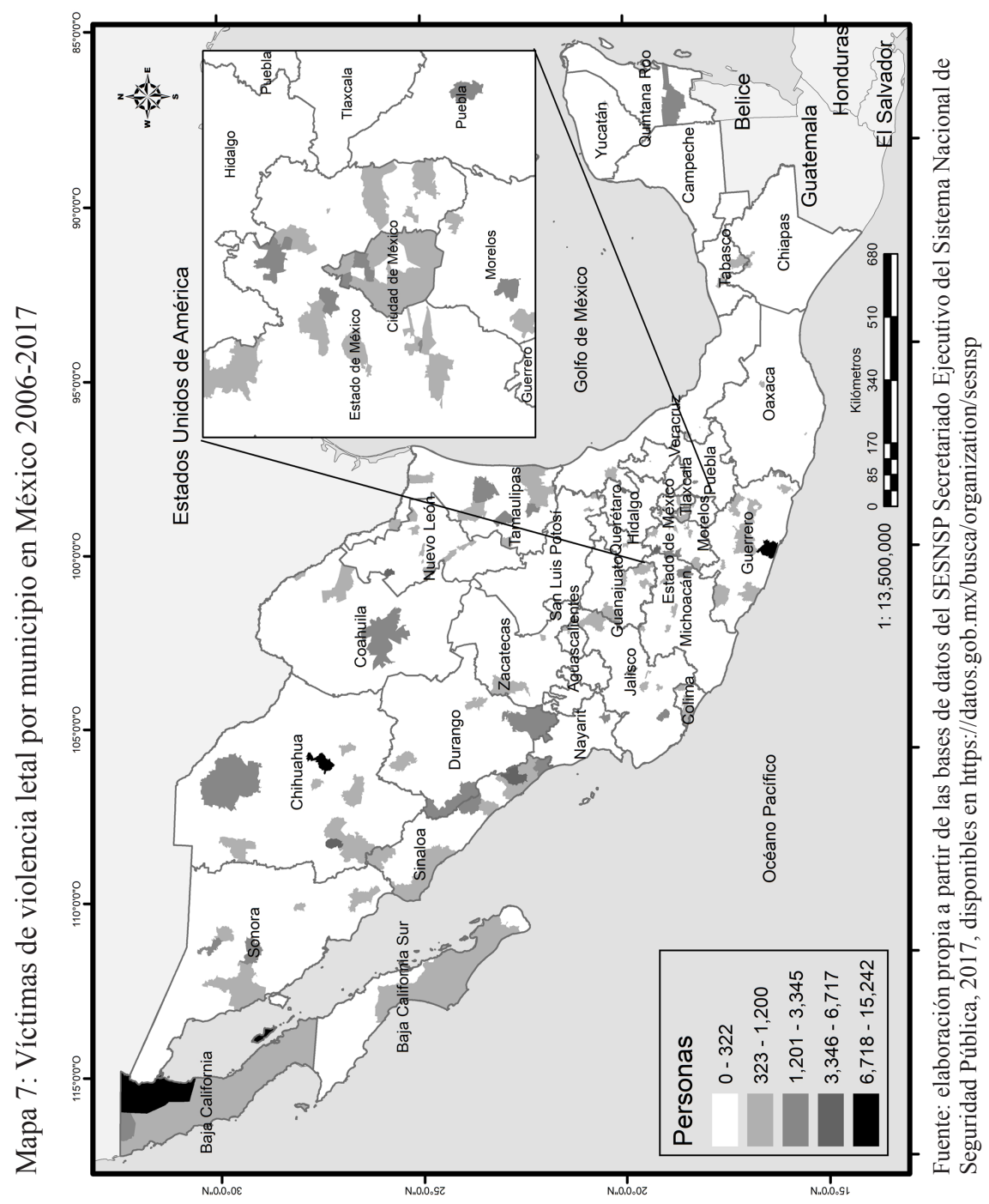




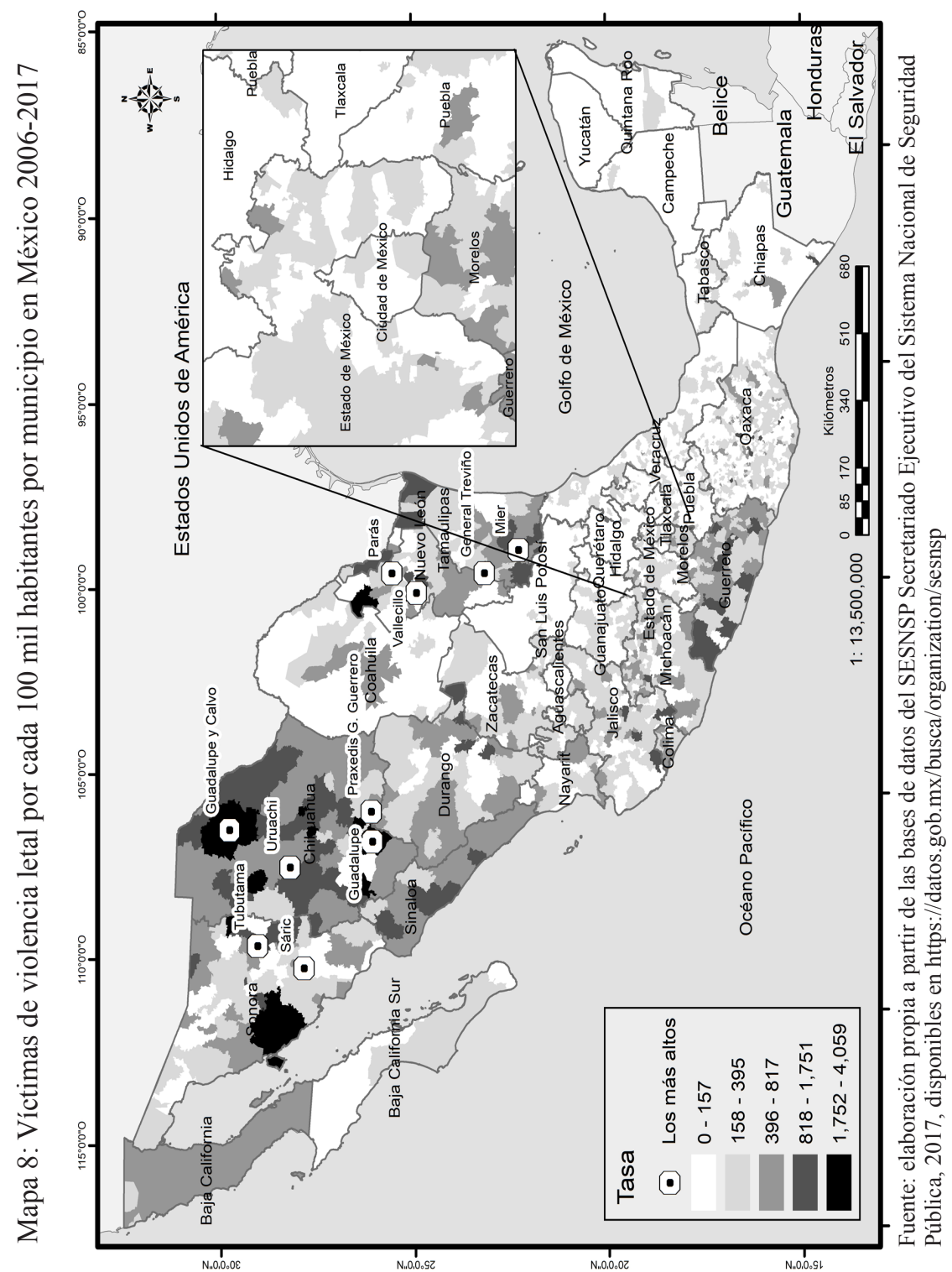


Geografía del terror: homicidios y desapariciones forzadas en los municipios de México 2006-2017 / E. CADENA y C. GARROCHO

\section{¿LA VIOLENCIA EXTREMA SE DISTRIBUYE ALEATORIAMENTE EN EL TERRITORIO O EXISTEN CLÚSTERS MUNICIPALES ESTADÍSTICAMENTE SIGNIFICATIVOS?}

Para determinar si un fenómeno está o no distribuido de manera aleatoria en el territorio, es preciso utilizar una medida de autocorrelación espacial. Quizá la más utilizada es el Índice de Moran. En esta sección se aplica esta técnica a los indicadores de violencia extrema, para develar si este tipo de violencia se distribuye aleatoriamente en México y entre los municipios del país.

En el caso del número de homicidios, desaparecidos y víctimas de la violencia letal, no hubo una autocorrelación espacial a escala del país, en virtud de que los valores del Índice Global de Moran (IGM) fueron muy bajos, lo que se explica por la enorme diversidad de la población municipal en el país. Para homicidios el IGM fue 0.041; para los desaparecidos 0.088; y para las víctimas de violencia letal, 0.044. Por tanto, es posible afirmar que, medido por números absolutos, no hay una tendencia a escala nacional a que los municipios donde existe un cierto número de casos de violencia extrema tengan como vecinos municipios con características semejantes.

En cambio, si medimos el IGM utilizando las tasas por cada 100 mil habitantes, lo que elimina la distorsión del tamaño de la población en cada municipio, los valores de los índices se elevaron considerablemente, indicando que la violencia extrema no se distribuye de manera aleatoria en la escala nacional. El IGM de las tasas de homicidios fue 0.320 ; el de las tasas de desaparecidos fue 0.260 ; y de 0.332 para la violencia letal. Los municipios tienden a agruparse en el territorio en función de sus niveles de violencia. Por tanto, es estratégico en términos de política pública (y privada) identificar los clusters de municipios, su área y la población que involucran. Este propósito no se puede lograr con estadística tradicional, se requiere estadística espacial, específicamente, el Î́ndice Local de Moran (Anselin, 1995).

\section{Clusters de municipios según su violencia extrema}

Los clusters de municipios según su incidencia delictiva pueden ser de cuatro tipos: i) Clusters de Alta Incidencia Delictiva (CAID). En este caso, todos los municipios que integran el cluster registran alta incidencia delictiva: la autocorrelación espacial de la ocurrencia de delitos es positiva y se denomina Alta-Alta); ii) Clusters de Baja Incidencia Delictiva 
(CBID). Están en la situación opuesta a la del inciso anterior: todos los municipios del cluster tienen baja incidencia delictiva, la autocorrelación espacial de la violencia extrema también es positiva y es referida como Baja-Baja); iii) Islas de Baja Incidencia Delictiva. Se componen de uno o varios municipios con baja incidencia delictiva, rodeados de municipios con alta incidencia delictiva: la autocorrelación espacial de la ocurrencia de delitos es negativa y se le llama Baja-Alta); iv) Focos de Alta Incidencia Delictiva (FAID). Son clusters integrados por uno o varios municipios con alta incidencia delictiva, rodeados de municipios con baja incidencia delictiva: la autocorrelación espacial de la ocurrencia de delitos es negativa y se le llama en la literatura Alta-Baja); finalmente, v) Clusters no significativos en términos estadísticos. Son conjuntos de municipios aglomerados/dispersos aleatoriamente, ya que no superan el nivel de significancia estadística establecido aquí de 99 por ciento.

\section{Homicidios}

Los Clusters de Alta Incidencia Delictiva incluyen 146 municipios que abarcan poco menos de 394.3 mil kilómetros cuadrados y afectaron directamente a más de 11.3 millones de personas (nueve por ciento de una población nacional estimada en 122 millones de personas en 2017 (Conapo, 2018). En este tema Chihuahua, Sinaloa y Guerrero fueron zonas de desastre, pero no son las únicas) (Ver Mapa 9). En Chihuahua resultó interesante el caso de los municipios de Guachochi como excepción a la violencia desatada (50 mil habs.) y también, aunque un poco menos por su tamaño poblacional, el de La Cruz (cuatro mil habs.). Sinaloa no registró municipios al margen de la violencia, a lo más que llega es a tener municipios que no tienen significancia estadística de ser parte del Cluster de Alta Incidencia Delictiva que cubre el resto del estado (e.g. El Fuerte, Ahome, Guasava, Escuinapa, Elota). En Guerrero, además de lo extendido de la Alta Incidencia Delictiva, incluye a dos destinos turísticos de gran importancia para el país: Acapulco e Ixtapa-Zihuatanejo.

Los Clusters de Baja Incidencia Delictiva se forman con $285 \mathrm{mu}-$ nicipios en un área de 145.4 mil kilómetros cuadrados, y más de 9.1 millones de habitantes ( 7.5 por ciento de la población total nacional). 
Geografía del terror: homicidios y desapariciones forzadas en los municipios de México 2006-2017 / E. CADENA y C. GARROCHO

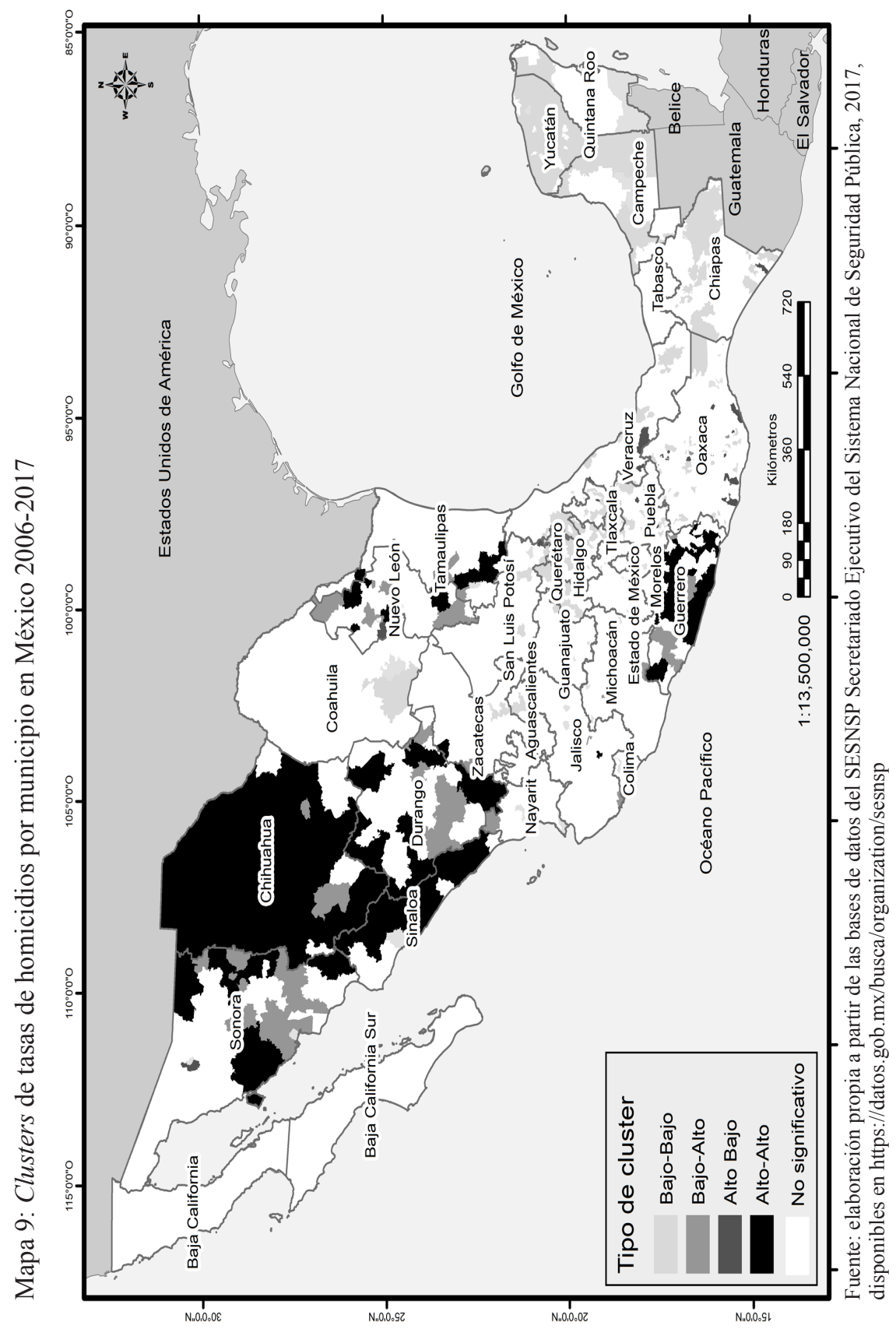


Son oasis de seguridad, agrupamientos de municipios en Yucatán (incluyendo la ciudad capital), Campeche (la inclusión del municipio de la capital está en duda: la autocorrelación no es significativa) y Chiapas (la capital puede no ser parte del cluster y destaca Huixtla como municipio de Alta Incidencia Delictiva: 54 mil habs.). Hay otros agrupamientos que salpican el territorio nacional, llamaría la atención uno al sur de Coahuila, pero revisándolo en detalle se observa que hay muy pocas localidades.

En cuanto a los clusters que son Islas de Baja Incidencia Delictiva apenas comprenden 44 municipios, 62.7 mil kilómetros cuadrados y 1.9 millones de habitantes. Es posible distinguir clusters de este tipo que están en riesgo de ser contaminados por la violencia en Sonora (es milagroso que el municipio de Nácori Chico que no sea de Alta Incidencia Delictiva), Chihuahua (Guachochi otro milagro que ya habíamos señalado), Durango (se observa un corredor de municipios que atraviesa desde los límites con Sinaloa a Zacatecas e incluye a la capital del estado), Guerrero (hay un corredor que va de Zihuatanejo, Coyuca de Catalán hasta Pungarabato) y Nuevo León (donde sorprende Anáhuac, municipio que hace frontera con Estados Unidos), entre otros.

Los clusters que son Focos de Alta Incidencia Delictiva sólo integran a 23 municipios que cubren un área de 10 mil 445 kilómetros cuadrados y alojaban 477.7 mil habitantes. En Nuevo León destaca el municipio de García (143 mil habs.), en Sonora: Tubutama (alrededor de dos mil habitantes) es un foco de Alta Violencia y en Veracruz lo es Tierra Blanca (alrededor de 100 mil habitantes).

Se puede decir que, en general, los municipios tienden a agruparse en términos de su incidencia delictiva y que encontrar municipios violentos con vecinos seguros y municipios seguros rodeados de municipios violentos es muy raro en México. La violencia parece tener un componente de difusión espacial, lo que sugiere que las Islas de Baja Incidencia Delictiva están en riesgo de desaparecer. El número de municipios que no presentan una relación estadística-espacial significativa son un mil 960, que suman un millón 300 mil kilómetros cuadrados, y en donde viven poco menos de 100 millones de personas: 83.3 por ciento del total nacional (Tabla 4). 
Geografía del terror: homicidios y desapariciones forzadas en los municipios de México 2006-2017 / E. CADENA y C. GARROCHO

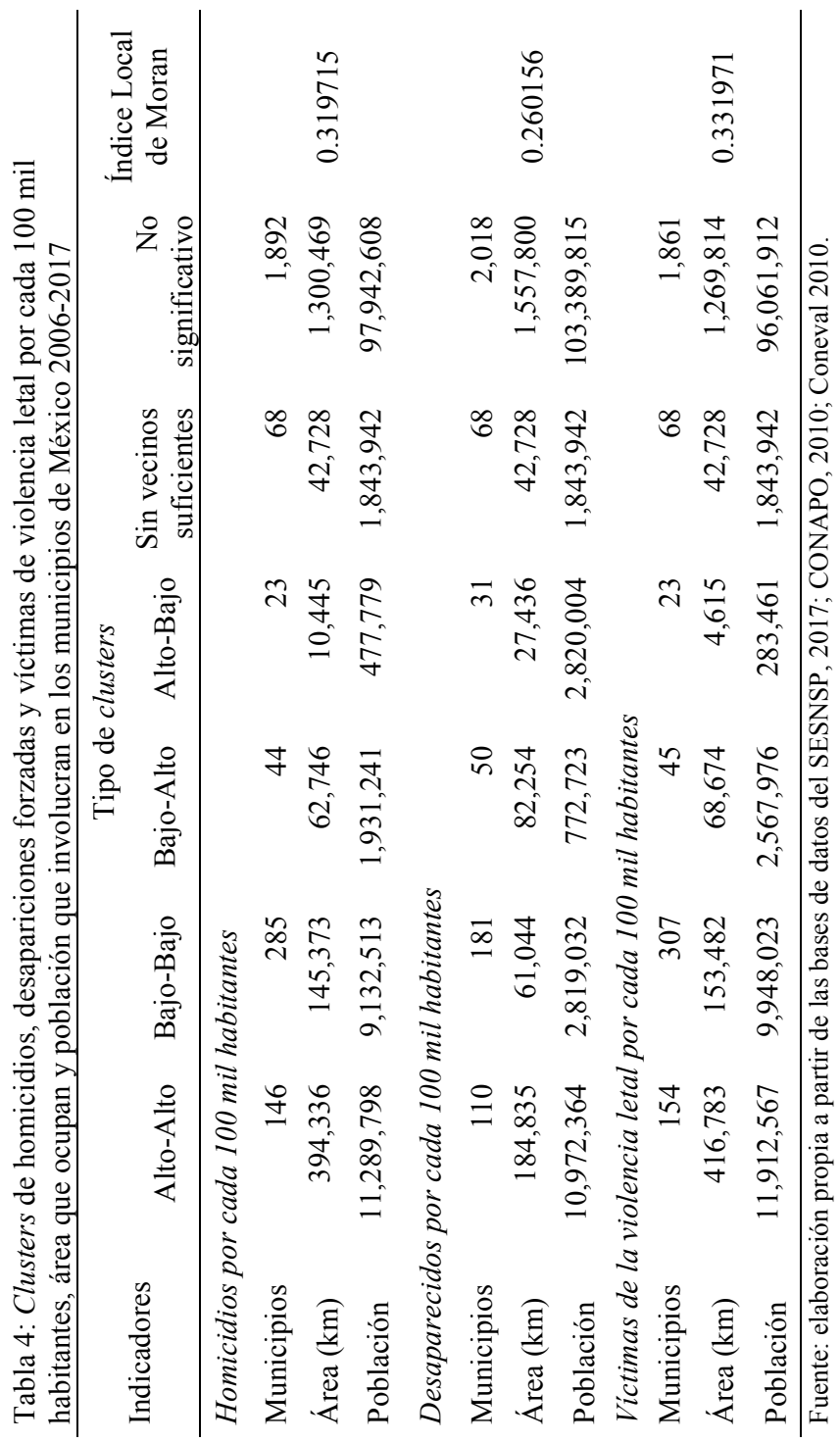




\section{Desapariciones forzadas}

110 municipios conforman los Clusters de Alta Incidencia Delictiva, y en ellos vivían 10.9 millones de habitantes en 184.8 mil kilómetros cuadrados. Destaca una región de terror que se extiende por Tamaulipas (todos los municipios del sur que limitan con San Luis Potosí y Veracruz hasta llegar al Golfo de México, y los del norte que hacen frontera con Estados Unidos, excepto: Gustavo Díaz Ordaz) Nuevo León (todos los municipios que limitan con Tamaulipas, excepto: Los Aldamas) y Coahuila (un corredor que cubre Múzquiz, Sabinas, Juárez) y otra región que cubre gran parte de Sinaloa (incluyendo Mazatlán y la capital: Culiacán). (Ver Mapa 10)

Los Clusters de Baja Incidencia Delictiva agrupan 181 municipios en 61 mil kilómetros cuadrados, donde residían 2.8 millones de personas. En esta categoría destacan agrupamientos de municipios importantes en Tabasco, Chiapas y Oaxaca. También algunos municipios de San Luis Potosí (e.g. la capital del estado) y Yucatán (e.g. Mérida: la ciudad más importante de la entidad).

Los Clusters Islas de Baja Incidencia Delictiva apenas agrupan a 50 municipios que suman un área de 82.2 mil kilómetros cuadrados y 773 mil habitantes. Prácticamente todas estas Islas de Baja Incidencia Delictiva se concentraban en los estados más comprometidos del país (los del norte de México) y están en alto riesgo de verse contagiados por la violencia extrema. Algunos ejemplos en Sonora son: Trincheras e Imuris; en Chihuahua: Cuauhtémoc y Riva Palacio; en Nuevo León: Los Herreras y Guadalupe; y en Tamaulipas: Ciudad Madero y González.

Por su parte, los Clusters Focos de Alta Incidencia Delictiva (e.g. municipios que pueden irradiar violencia extrema a sus vecinos) sólo integran 31 municipios en un área apenas superior a los 27.4 mil kilómetros cuadrados, donde vivían dos millones 820 habitantes. Destaca un agrupamiento importante de municipios entre Durango, Nayarit y Zacatecas (e.g. el occidente de México y la entrada a Sinaloa); municipios como Cajeme y San Ignacio Río Muerto en Sonora, Cuetzala del Progreso en Guerrero, San Andrés Cholula en Puebla, Yanga y La Antigua en Veracruz y, muy relevante (por el entorno de seguridad): Xocchel en Yucatán.

En dos mil 18 municipios no hay una relación estadística y espacial significativa, y vivían 103 millones de personas (85.8 por ciento del total nacional) en un área de un millón y medio de kilómetros cuadrados (Tabla 4). 
Geografía del terror: homicidios y desapariciones forzadas en los municipios de México 2006-2017 / E. CADENA y C. GARROCHO

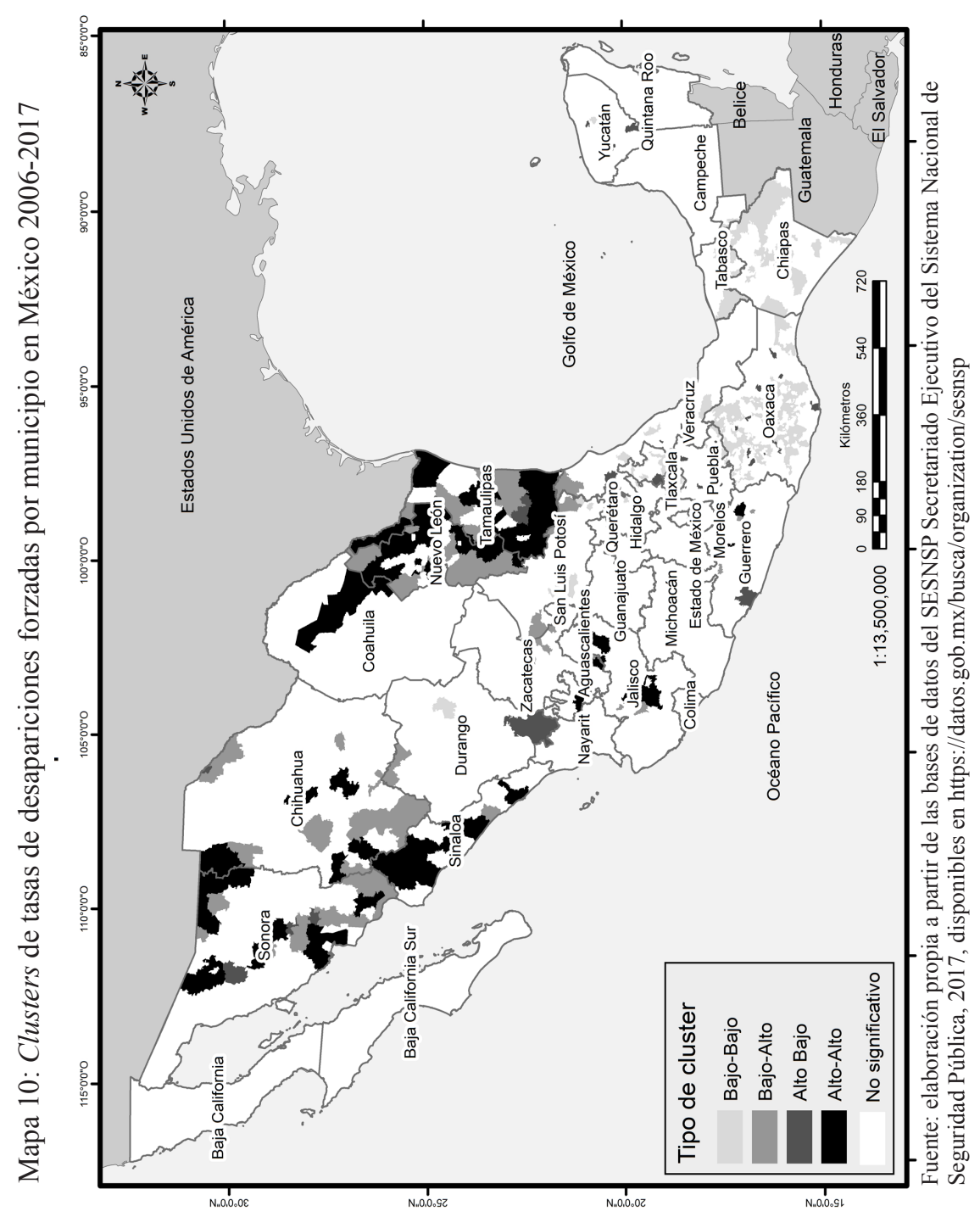


Agrupados homicidios y desapariciones forzadas, los Clusters de Alta Incidencia Delictiva de víctimas de la violencia letal suman 154 municipios donde habitaban casi 12 millones de personas en un área de 416.7 mil kilómetros cuadrados. Los Clusters de Baja Incidencia Delictiva integran 307 municipios en 153.4 mil kilómetros cuadrados y 9.9 millones de personas. Los Clusters Islas de Baja Incidencia Delictiva Bajo-Alto, suman 45 municipios, un área de 68.6 mil kilómetros cuadrados y 2.5 millones de personas. Finamente, los Clusters Focos de Alta Incidencia Delictiva, agrupan 23 municipios, 4.6 mil kilómetros cuadrados y 283 mil personas (Tabla 4) (Ver Mapa 11).

\section{REgIONES PRIORITARIAS DE ATENCIÓN PARA PREVENIR}

\section{LA VIOLENCIA EXTREMA}

Un problema metodológico para el análisis de la violencia extrema (homicidios, desapariciones forzadas y la sumatoria de ambas) fue que sus indicadores se encuentran en unidades distintas (números absolutos y tasas) y los universos a los que se refieren son de tamaños en extremo disímbolos, ya que hay municipios de menos de mil habitantes y otros de más de un millón. Esto provoca una situación en la que hay municipios con un alto número de homicidios, pero su tasa de homicidios es baja, y, al mismo tiempo, hay municipios con tasas muy altas de violencia, pero con números relativamente bajos de víctimas.

Una clasificación adecuada de municipios por sus niveles de violencia debe englobar los dos criterios de medición (e.g. absoluto y relativo), bajo el principio de que es tan grave el hecho de que existan municipios donde muchas personas fueron víctimas de violencia extrema (e.g. números absolutos), como que existan municipios donde se registra una alta intensidad de la violencia (e.g. números relativos o tasas) independientemente de su tamaño poblacional.

Para salvar este problema taxonómico, se utilizó el método de Jenks que se basa en clasificar por etapas, donde cada uno de los seis indicadores de violencia se estratificó en cinco grupos y después todas las clasificaciones se combinaron en una sola (Wang et al., 2019). Se establecieron cinco niveles de violencia combinada, que considera tanto números absolutos (e.g. personas) como números relativos (e.g. tasas), para homicidios, desapariciones y su sumatoria. Esta clasificación de niveles de violencia se expresa como: violencia Muy Baja (estrato 1), Baja (estrato 2), Media (estrato 3), Alta (estrato 4) y Muy Alta (estrato 5). 
Geografía del terror: homicidios y desapariciones forzadas en los municipios de México 2006-2017 / E. CADENA y C. GARROCHO

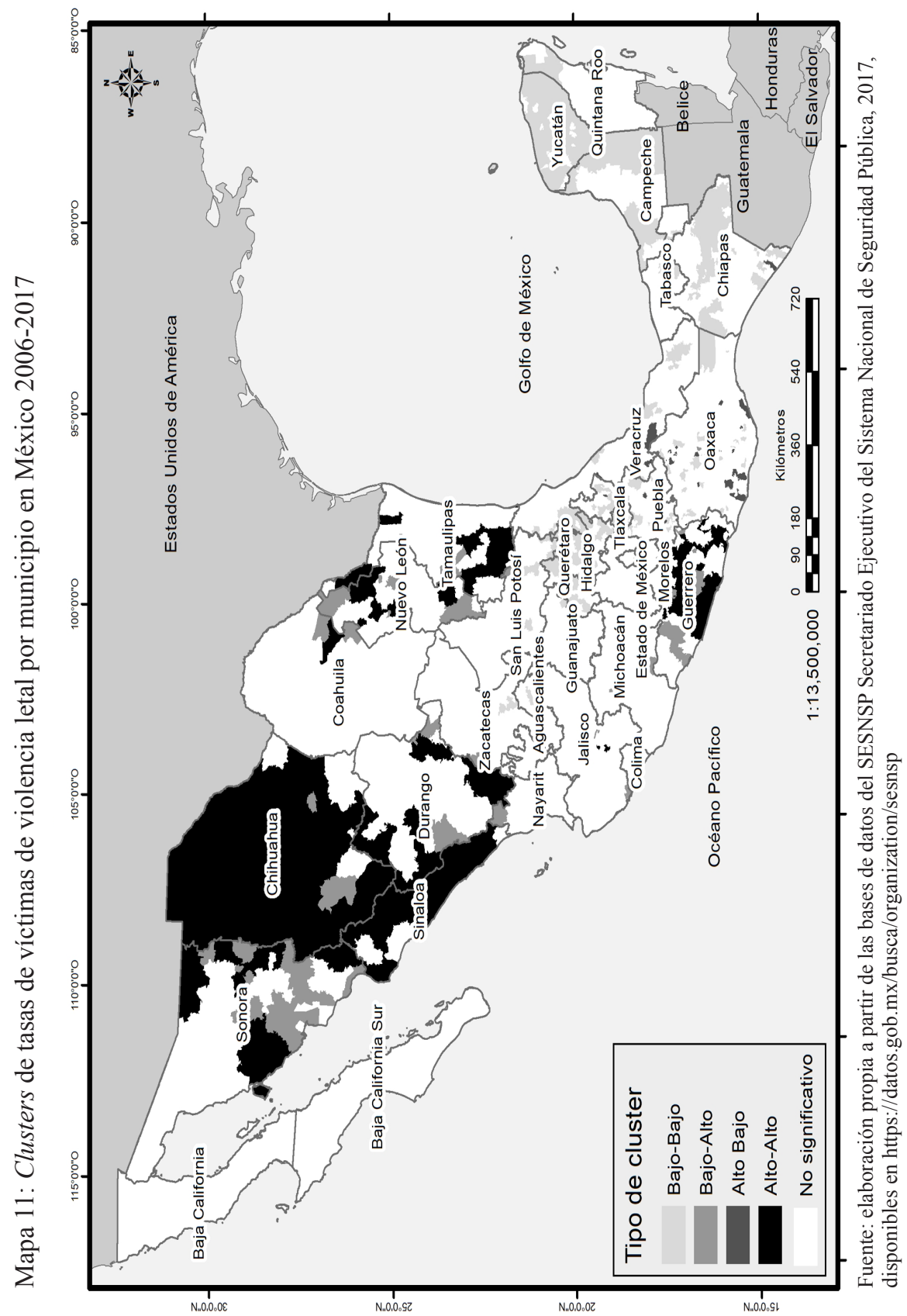


El resultado es que estados como Sinaloa, Baja California, Colima, Nuevo León, y Tamaulipas tuvieron entre la décima y más de la cuarta parte de sus municipios en el estrato de Alta violencia (estrato 5). En cambio, en 20 estados no registraron un solo municipio en ese estrato de violencia. Estos estados son: Aguascalientes, Baja California Sur, Campeche, Chiapas, Ciudad de México, Guanajuato, Hidalgo, Michoacán, Morelos, Nayarit, Oaxaca, Puebla, Querétaro, Quintana Roo, San Luis Potosí, Tabasco, Tlaxcala, Veracruz, Yucatán, y Zacatecas (Tabla 5).

Si se agrupan en una sola categoría los estratos de violencia Alta y Muy Alta (estratos 4 y 5), entonces los estados que tuvieron más de diez por ciento de sus municipios en dicha clasificación fueron: Sinaloa, Baja California, Tamaulipas, Chihuahua, Colima, Nuevo León, Ciudad de México, Guerrero, Sonora, y Durango. En el caso opuesto están Aguascalientes, Baja California Sur, Campeche, Chiapas, Guanajuato, Hidalgo, Nayarit, Querétaro, Tabasco, Tlaxcala, Veracruz, y Yucatán, ya que ninguno de sus municipios se ubicó en los estratos de violencia Alta y Muy Alta (Tabla 5).

Los estratos más Altos de violencia se ubicaron en un gran corredor de municipios que va desde Guerrero hasta la frontera con Estados Unidos, incluyendo casi todos los municipios de la península de Baja California (en Baja California Sur se salvan Mulegé, Loreto y Los Cabos, pero no Comondú ni La Paz), las alcaldías y municipios de la zona metropolitana de la Ciudad de México, el Estado de México y Morelos, pero alcanzando las cotas más elevadas en municipios de Sinaloa, Chihuahua, Sonora y Durango. Otra región de Alta y Muy Alta violencia fue la que abarca casi la totalidad de municipios de Tamaulipas (sólo se salvan Soto la Marina, Villagrán, Burgos, Méndez y Cruillas), Nuevo León (incluyendo a Monterrey: la segunda ciudad más poblada del país) y parte de Coahuila (destacando Cuatrociénagas). En el otro extremo del espectro de la violencia (donde predomina la violencia Muy Baja) se distinguen dos regiones: una que contiene municipios de San Luis Potosí, Querétaro e Hidalgo (incluyendo los municipios de las capitales), y otra conformada por municipios de estados del sureste del país, exceptuando Quintana Roo donde se registró violencia Alta en Solidaridad (donde se localizan Playa del Carmen) y en Compostela Tulum, dos de los principales destinos turísticos internacionales de México (Mapa 12). 
Geografía del terror: homicidios y desapariciones forzadas en los municipios de México 2006-2017 / E. CADENA y C. GARROCHO

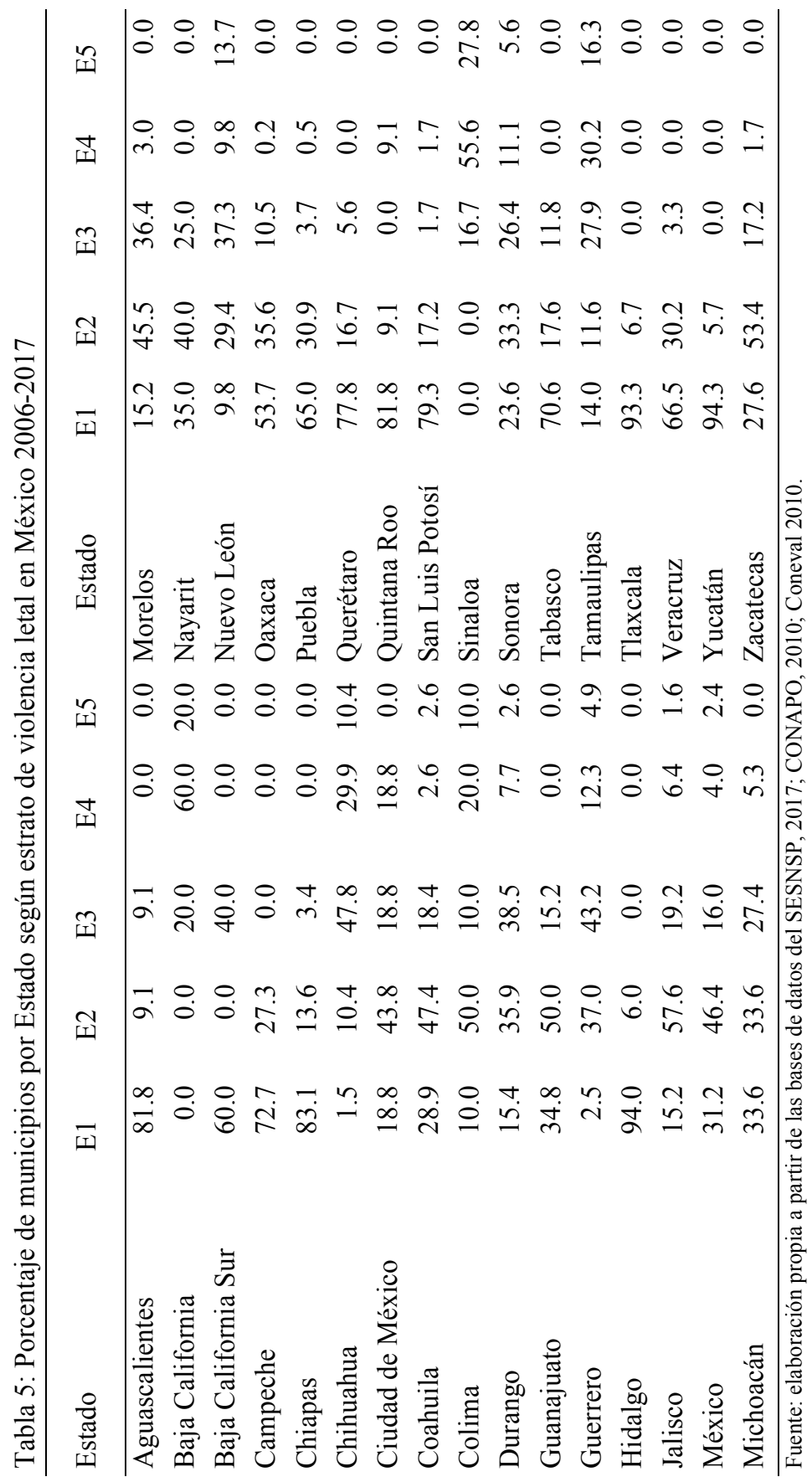




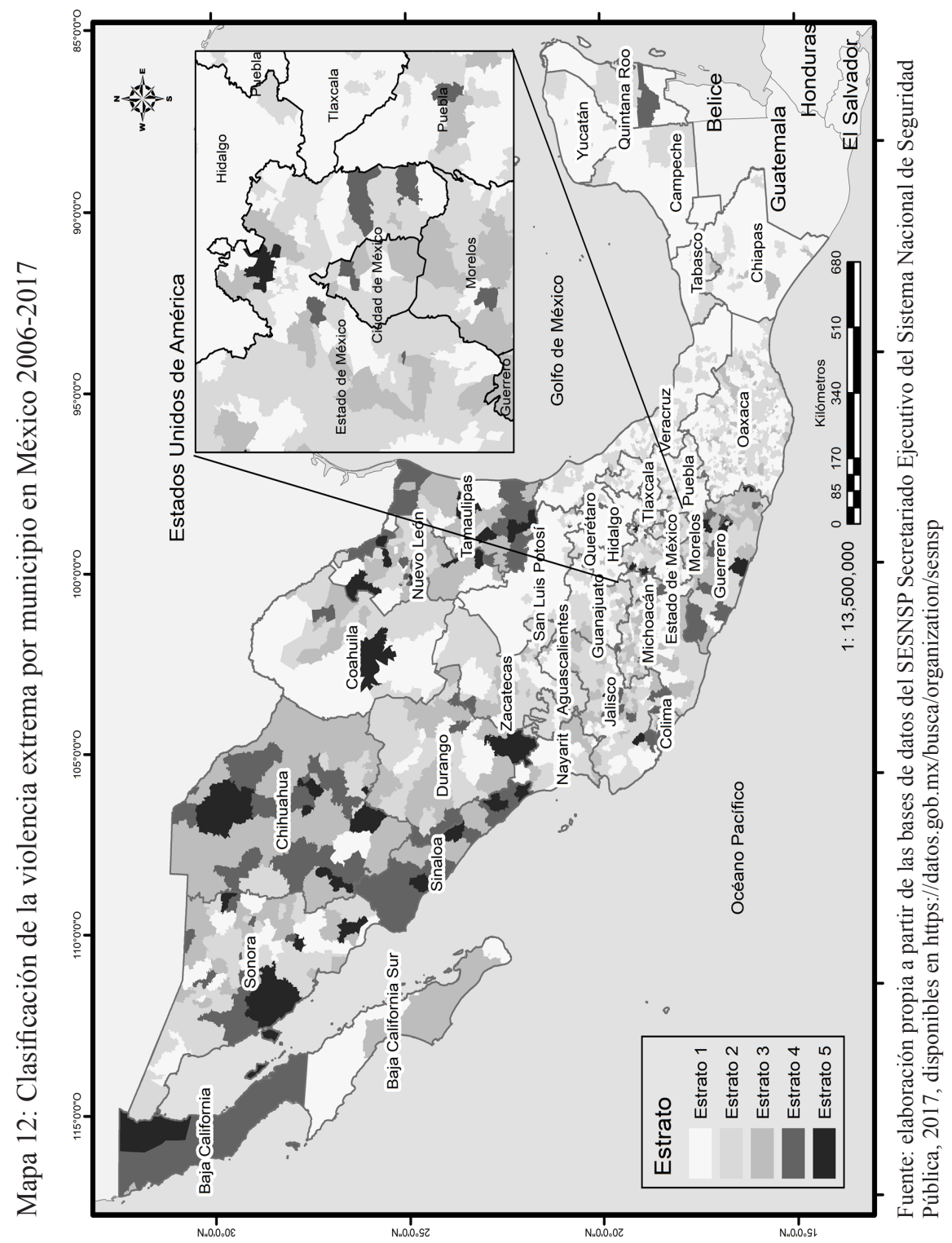


Si se agrupan los estratos 3, 4 y 5 de violencia, entonces dos estados (Sinaloa y Baja California) registraron la totalidad de sus municipios en los niveles de violencia Media, Alta y Muy Alta. Cuatro estados más tuvieron más de la mitad de sus municipios en esas situaciones de violencia (Chihuahua, Tamaulipas, Nuevo León, y Guerrero) y 11 más (Durango, Sonora, Colima, Baja California Sur, Morelos, Ciudad de México, Michoacán, Jalisco, Nayarit, Coahuila, y Estado de México) registraron entre 20 y 50 por ciento de sus municipios en estas categorías de violencia. En el caso contrario, en sólo cuatro estados no se tuvo un solo municipio en niveles de violencia Media, Alta y Muy Alta: Campeche, Hidalgo, Tlaxcala y Yucatán.

\section{¿LA VIOLENCIA EXTREMA EN LOS MUNICIPIOS SE RELACIONA ESTADÍSTICAMENTE CON LA ADVERSIDAD SOCIAL MUNICIPAL?}

El propósito de esta sección fue explorar si existen correlaciones estadísticamente significativas entre los indicadores de adversidad social que hemos seleccionado y los eventos de violencia extrema registrados en carpetas de investigación entre 2006 y 2017, a escala municipal. Se parte del supuesto, debatible, que la gran mayoría de los eventos de violencia extrema se registran judicialmente en el municipio donde ocurrió el delito. Este supuesto también lo asume el SESNSP en sus estadísticas de incidencia delictiva (SESNSP, 2019a y 2019b). Estimamos correlaciones sólo para tasas de incidencia delictiva por 100 mil habitantes, tanto por razones de espacio como para eliminar el efecto distorsionante del tamaño de la población. Veamos.

La marginación registró correlaciones nulas con las tasas de homicidios (0.026), desapariciones forzadas (-0.128) y con víctimas de violencia letal (-0.019). En el caso del rezago social, las correlaciones con las tasas de incidencia delictiva fueron prácticamente igual de bajas y dos de ellas tuvieron signo negativo (contrario a lo esperado). Lo mismo ocurrió con la desigualdad en la distribución del ingreso (Coeficiente de Gini): las correlaciones rondan el cero y ninguna rebasa 0.120 . Estas tres variables parece que no son variables estratégicas para explicar estadísticamente la violencia extrema (Tabla 6).

Correlacionado el porcentaje de personas pobres con las tasas de violencia extrema, se ve que es muy bajo y muestra el signo contrario al esperado por el discurso gubernamental y por algunos estudios en Latinoamérica (todos son negativas). Por su parte, la correlación del número de pobres con la tasa de desapariciones forzadas por 100 mil habitantes es casi cero $(-0.015)$. 
Tabla 6: Correlaciones entre tasas de homicidios, desapariciones forzadas y víctimas de violencia letal con indicadores de adversidad social 2006-2017

\begin{tabular}{lrrr}
\hline & \multicolumn{3}{c}{ Tasas por 100 mil habitantes } \\
\cline { 2 - 4 } & Homicidios & $\begin{array}{r}\text { Desapariciones } \\
\text { forzadas }\end{array}$ & $\begin{array}{r}\text { Víctimas de } \\
\text { violencia letal }\end{array}$ \\
\hline Índice de marginación & 0.026 & $* *-0.128$ & -0.019 \\
Índice de rezago social & 0.027 & $* *-0.144$ & -0.017 \\
Coeficiente de Gini & -0.022 & $* *-0.111$ & -0.032 \\
Personas pobres & $* * 0.015$ & $*-0.069$ & -0.005 \\
Porcentaje de personas pobres & $* *-0.139$ & $* *-0.178$ & $* *-0.177$ \\
\hline * La correlación es significativa en el nivel 0,05 (bilateral). & & \\
$* *$ La correlación es significativa en el nivel 0,01 (bilateral). & &
\end{tabular}

Así las cosas, tampoco hay relación estadística entre los indicadores de pobreza y la tasa de desapariciones forzadas. Por su parte, las correlaciones entre número de pobres con las tasas de violencia extrema también son muy bajas: tienden a cero (Tabla 6).

Al parecer, la adversidad social no está relacionada estadísticamente con la incidencia de violencia extrema, considerando información agregada por municipio e incluyendo todos los municipios de México. Una manera de probar esta declaración es someterla a una prueba de contraste. Por ello se comparó lo ocurrido en los municipios de entidades con Alta y Baja Incidencia de Violencia Extrema. Sinaloa y Chihuahua están en el primer caso, Aguascalientes y Yucatán, en el segundo. Se calcularon las correlaciones entre los indicadores de adversidad social y las tasas de incidencia de violencia extrema. Se usaron tasas para evitar el efecto distorsionante del tamaño de la población municipal. Si el discurso gubernamental (y varios estudios latinoamericanos) es correcto, las correlaciones apuntarían en el mismo sentido (serían similares al menos en el signo) para los municipios de los dos tipos de entidades. Es decir, las tasas de incidencia de violencia extrema se asociarían positivamente a los indicadores de adversidad social: municipios con alta incidencia de violencia extrema registrarían alta adversidad social y viceversa.

En los estados con Alta incidencia de violencia extrema (Chihuahua y Sinaloa) las tasas de homicidios sí registraron correlaciones positivas y estadísticamente significativas al 99 por ciento con la marginación (0.460), rezago social (0.474) y porcentaje de personas en pobreza (0.449) (Tabla 7). 
Geografía del terror: homicidios y desapariciones forzadas en los municipios de México 2006-2017 / E. CADENA y C. GARROCHO

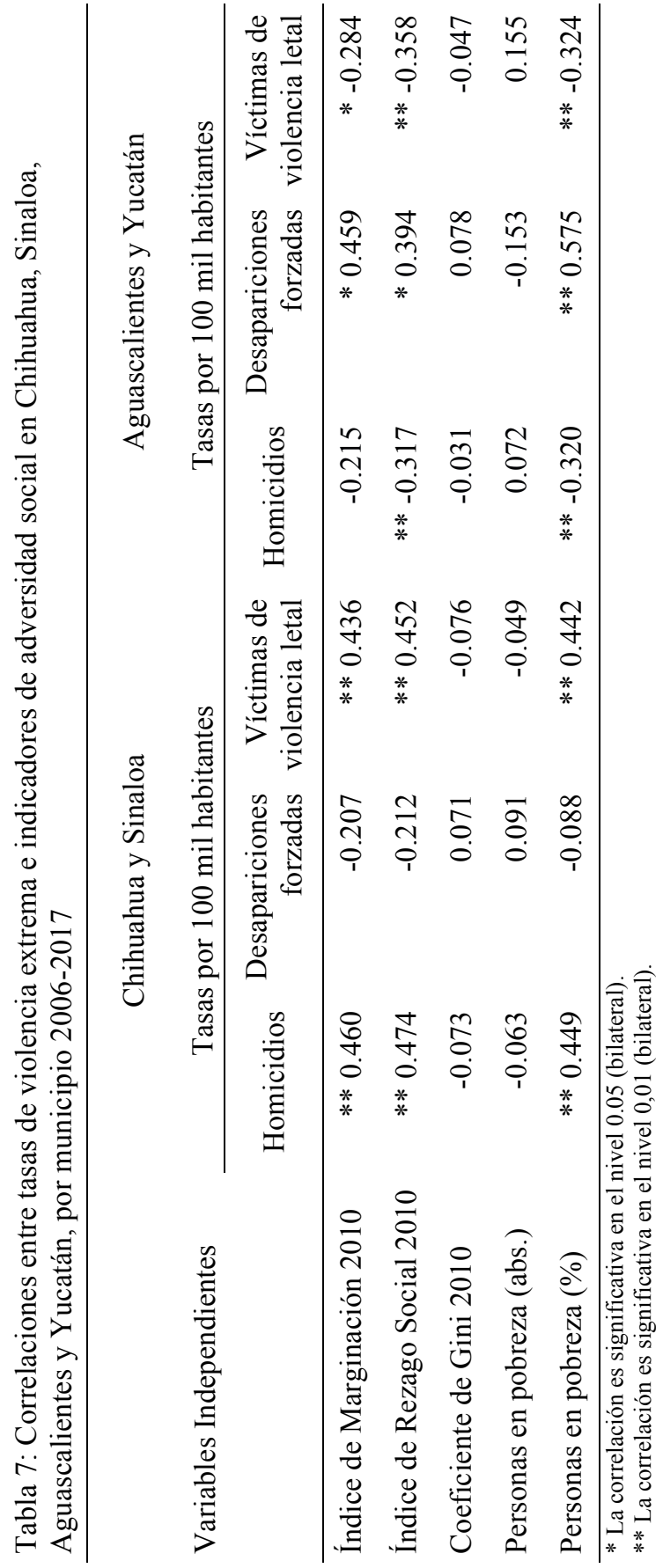


En estas entidades, las más violentas del país a escala estatal y municipal, sí es correcto afirmar que "a mayor adversidad social mayor incidencia de homicidios". En cambio, las correlaciones de la adversidad social y la tasa de desapariciones forzadas fueron bajas y no significativas, lo que indica que la incidencia de violencia extrema es más compleja de lo que sintetiza la tesis gubernamental y algunos estudios de nuestro subcontinente.

Por su parte, en los estados más seguros (Aguascalientes y Yucatán), las correlaciones entre las tasas de homicidios y los indicadores de adversidad social registraron correlaciones estadísticamente significativas al 99 y 95 por ciento, pero los signos son contrarios a los de las entidades de mayor incidencia de violencia extrema (e.g. Chihuahua y Sinaloa): los tres son negativos. Las correlaciones son -0.215 con marginación, -0.317 con rezago social y -0.320 con el porcentaje de personas en pobreza. Sería erróneo y simplista decir que, en los estados más seguros del país, "a mayor adversidad social, menor incidencia de homicidios". La historia debe ser otra y más compleja.

No obstante, las desapariciones forzadas en los municipios de Aguascalientes y Yucatán sí registraron correlaciones positivas y significativas con las mismas variables de adversidad social: con marginación (0.459), con rezago social (0.394) y con porcentaje de personas en pobreza (0.575). En este tipo de delito sí parecería que a "mayor adversidad social, mayor incidencia de desapariciones forzadas", incluso en los estados más seguros del país. La discordancia de estas correlaciones con las reveladas en Chihuahua y Sinaloa es notable: en estos estados las correlaciones de adversidad social con desapariciones forzadas son bajas y no significativas.

Esta mezcla de coeficientes de correlación no significa, por ningún motivo, que para hacer más seguros a los estados seguros se deba incrementar la marginación, el rezago social y el porcentaje de personas en pobreza, pero tampoco, que sólo por reducir la adversidad social se logrará reducir la incidencia de violencia extrema. Lo que sugiere este análisis estadístico de contraste (a escala municipal), es que la incidencia de violencia extrema se relaciona con múltiples variables que van más allá de la pura adversidad social, por ejemplo: características de los municipios como productores de drogas, como puntos de entrada y salida de sustancias (puntos de salida: Tijuana, Ciudad Juárez, Reynosa, Laredo; puntos de entrada: Manzanillo, Colima, por donde ingresa gran parte del fentanilo proveniente de China); como mercados de consumo que generan disputas entre cárteles (usualmente en ciudades grandes con municipios y colonias con menos presencia de fuerzas de seguridad: Zonas Metropolitanas de la Ciudad de México, 
Monterrey o Guadalajara); de sus sociedades locales: valores, tradiciones, historia (e.g. la tradición de Sinaloa como productores de amapola derivada de la influencia inmigratoria china); de los individuos en toda su complejidad personal (ver la sección de revisión de la literatura); de la debilidad / corrupción de las instituciones a diversas escalas espaciales. Por su parte, las desapariciones forzadas parecen seguir una lógica geográfica diferente a los homicidios: no responden sólo a la pobreza y violencia del municipio donde ocurren, sino a otras circunstancias, incluso a las condiciones de prosperidad del municipio donde se llevan a cabo las desapariciones forzadas, como puede ser en el caso de los secuestros. Explorar estos temas requiere investigación a profundidad que está fuera del alcance de este trabajo y más allá de las capacidades de los autores. En todo caso, lo más importante aquí es reconocer que es equivocado pensar que sólo por reducir la adversidad social se logrará reducir la incidencia de violencia extrema. Se requieren múltiples medidas adicionales.

\section{Conclusiones}

La principal aportación de este trabajo fue develar la dinámica de la violencia extrema en México con un enfoque multiescalar: nacional, estatal y, primordialmente, municipal. Hacer un zoom a la escala municipal permitió descubrir una realidad desconocida de la violencia extrema en México y ofrecer información estratégica para la acción pública. No se encontró ningún trabajo de este tipo en nuestro país ni en Latinoamérica. Esta investigación contribuye a llenar este hueco en la literatura especializada sobre uno de los mayores problemas de México y diversos países de la región en el siglo XXI.

La primera conclusión que se deriva de los datos disponibles es que la incidencia de violencia extrema registraba una tendencia a la baja desde el gobierno de Vicente Fox, tanto en números absolutos como en tasas por 100 mil habitantes. La paradoja es que a partir de la declaración de la "Guerra contra el Narco" de Felipe Calderón la violencia extrema se disparó hasta llegar a récords históricos durante el gobierno de Enrique Peña Nieto. Revertir la tendencia no va a ser fácil, ni rápido, ni barato.

Si se comparan tasas de incidencia delictiva extrema por 100 mil habitantes, es equivocado afirmar que México es de los países más violentos del mundo. Incluso en Latinoamérica hay diversos países con tasas varias veces más altas que en el nuestro. En la escala estatal se perfila que, como en muchos temas, en incidencia de violencia extrema existen varios Méxicos. Uno seguro y en paz (e.g. Aguascalientes, Campeche, Yucatán) y otro 
de violencia desatada (e.g. Chihuahua, Guerrero, Sinaloa). Sin embargo, es en la escala municipal donde el perfil de la violencia extrema se manifiesta con sus detalles de terror: es verdad que algunos de los municipios de México son de los lugares más peligrosos del planeta en términos de tasas de homicidios y desapariciones forzadas. Lamentablemente, la mayoría de estos municipios son desconocidos por el grueso de la población, ya que rara vez aparecen en el discurso del gobierno federal o en los medios de comunicación nacional. Contra lo que muchos creen, los municipios y alcaldías de la zona metropolitana de la Ciudad de México no están entre los más peligrosos del país (el más peligroso es Venustiano Carranza y ocupa el lugar 527 de 2 mil 458 en la jerarquía municipal por tasa de violencia letal).

La violencia extrema no se distribuye aleatoriamente en el territorio, sino que existen clusters municipales estadísticamente significativos, según sus tasas por 100 mil habitantes. Se identificaron estos clusters y se clasificaron en cinco categorías: i) Clusters de Alta Incidencia Delictiva, que son regiones prioritarias de atención, estratégicos para reducir la incidencia de violencia extrema; ii) Clusters de Baja Incidencia Delictiva, que integran municipios seguros que es imperioso resguardar; iii) Islas de Baja Incidencia Delictiva, que son conjuntos compuestos por uno o varios municipios con baja incidencia delictiva, rodeados de municipios con alta incidencia delictiva, que requieren medidas para prevenir la difusión de la violencia; y, iv) Focos de Alta Incidencia Delictiva (FAID), que son clusters integrados por uno o varios municipios con alta incidencia delictiva, rodeados de municipios con baja incidencia delictiva. En estos clusters se requieren medidas puntuales para eliminar el foco difusor de violencia extrema. Cada tipo de cluster requiere acciones "a la medida", por lo que develarlos puede ser muy útil para la toma de decisiones públicas y privadas.

Finalmente, el análisis estadístico de contraste a escala municipal, indica que la incidencia de violencia extrema se relaciona con múltiples variables que van más allá de la pura adversidad social. En otras palabras, asegurar que la incidencia delictiva depende de remediar la adversidad social, es simplista porque ignora la complejidad del fenómeno, así como las diversas dimensiones: del impacto del narcotráfico: producción, distribución, consumo, geografía socioeconómica de los mercados, lavado de ganancias, corrupción pública y privada, tradiciones e historias locales, entre muchas otras. Avanzar en varias de estas dimensiones requiere investigación a profundidad fuera del alcance de esta investigación. 
Geografía del terror: homicidios y desapariciones forzadas en los municipios de México 2006-2017 / E. CADENA y C. GARROCHO

\section{REFERENCIAS BIBLIOGRÁFICAS}

Acero González, Á R; Escobar Córdoba, F; Castellanos Castañeda, G., 2007, "Factores de riesgo para violencia y homicidio juvenil", en Revista Colombiana de Psiquiatría, XXXVI, 78-97. Recuperado de http://www.redalyc.org/articulo. oa? id=80636107

Álvarez, Á E., 2010, "Determinantes institucionales de la violencia criminal en Venezuela", en Politeia, 33, 91-118. Recuperado de http://www.redalyc.org/articulo.oa?id=170020031004

Anselin, Luc, 1995, "Local indicators of spatial association-LISA", en Geographical Analysis, 27 (2), p. 93-115. Recuperado de https://onlinelibrary.wiley.com/ doi/pdf/10.1111/j.1538-4632.1995.tb00338.x

Arroyo Juárez, M., 2001, “Características y situación del homicidio en la Zona Metropolitana de la Ciudad de México 1993-1997", en Papeles de Población, 7, 233-245. Recuperado de http://www.redalyc.org/articulo.oa?id=11273010

Bergman, M., 2012, "La violencia en México: algunas aproximaciones académicas", en Desacatos. Revista de Ciencias Sociales, 65-76. Recuperado de http:// www.redalyc.org/articulo.oa?id=13925007005

Bonilla Mejía, L., 2010, "Demografía, juventud y homicidios en Colombia, 19792006", en Lecturas de Economía,103-140. Recuperado de http://www.redalyc. org/articulo.oa? id=155216291005

Briceño-León, R., 2002, "La nueva violencia urbana de América Latina", en Sociologias, 4, 34-51. Recuperado de http://www.redalyc.org/articulo. oa? id $=86819566003$

Briceño-León, R., 2008, "La violencia homicida en América Latina", en América Latina Hoy, 50, 103-116. Recuperado de http://www.redalyc.org/articulo. oa? id=30810929007

Briceño-León, R., 2012, “La Comprensión de los Homicidios en América Latina: ¿Pobreza o Institucionalidad?”, en Ciência and Saúde Coletiva, 17, 3159-3170. Recuperado de http://www.redalyc.org/articulo.oa?id=63024424002

Buvinic, M; Morrison, A; Orlando, M. B., 2005, "Violencia, crimen y desarrollo social en América Latina y el Caribe", en Papeles de Población, 11, 167-214. Recuperado de http://www.redalyc.org/articulo.oa?id=11204309

Cardona, M; García, H I; Giraldo, C A; López, M V; Suárez, C M; Corcho, D C; Posada, C. H., 2005, "Escenarios de homicidios en Medellín (Colombia) entre 1990-2002”, en Revista Cubana de Salud Pública, 31, 202-210. Recuperado de http://www.redalyc.org/articulo.oa?id=21431305

Carranza Romero, J E; Dueñas Herrera, X; Gonzélez Espitia, C. G., 2011, “Análisis empírico de la relación entre la actividad económica y la violencia homicida en Colombia", en Estudios Gerenciales, 27, 59-77. Recuperado de http://www. redalyc.org/articulo.oa? $\mathrm{id}=21220043003$ 
Carrión M., F., 2005, “La inseguridad ciudadana en América Latina”, en Quórum. Revista de pensamiento iberoamericano, núm. 12, otoño, 2005 29-52. Recuperado de http://www.redalyc.org/articulo.oa?id=52001204

Castellano Durán, R. y Castellano González, R. D., 2012, “Agresión y violencia en América Latina. Perspectivas para su estudio: Los otros son la amenaza", en Espacio Abierto, 21, 677-700. Recuperado de http://www.redalyc.org/articulo. oa? id $=12224818004$

Cervantes Loredo, M., 2015, “La participación social en familias víctimas de desaparición involuntaria”, en RICSH Revista Iberoamericana de las Ciencias Sociales y Humanísticas, 4 (8). Recuperado de http://www.redalyc.org/articulo. oa? $\mathrm{id}=503950656004$

CONAPO, 2010, Índice de Marginación por entidad federativa y municipio 2010, México: Consejo Nacional de Población (CONAPO). Recuperado de http://www. conapo.gob.mx/en/CONAPO/Indices_de_Marginacion_2010_por_entidad_federativa_y_municipio

CONAPO, 2018, Proyecciones de la Población de México y de las Entidades Federativas, 2016-2050. Consejo Nacional de Población. Disponible en https://datos.gob.mx/busca/dataset/proyecciones-de-la-poblacion-de-mexico-y-de-las-entidades-federativas-2016-2050

Concha, A., 2002, "Impacto social y económico de la violencia en las Américas", en Biomédica 22, 347-361. Recuperado de http://www.redalyc.org/articulo. oa? $\mathrm{id}=84309604$

CONEVAL, 2018, Anexo estadístico de pobreza a nivel municipio 2010 Y 2015, México, Consejo Nacional de Evaluación de la Política de Desarrollo Social (CONEVAL). Recuperado de https://www.coneval.org.mx/Medicion/Paginas/AE_pobreza_municipal.aspx

CONEVAL, 2010, Índice de Rezago Social 2010 a nivel municipal y por localidad, México: Consejo Nacional de Evaluación de la Política de Desarrollo Social (CONEVAL). Recuperado de https://www.coneval.org.mx/Medicion/IRS/Paginas/Índice-de-Rezago-social-2010.aspx

Chávez-Soto, Tania y Garrocho, Carlos, 2018, "Estación de Inteligencia Territorial: CHRISTALLER ${ }^{\circ}$, GeoSig, 10 (10), Recuperado de https://docs.wixstatic. com/ugd/79758e_06e66947b32a48369bf75f7c80a378c0.pdf

Echandía Castilla, C., 2001, "La violencia en el conflicto armado durante los años 90", en Revista Opera, 1, 229-245. Recuperado de http://www.redalyc.org/articulo.oa? $\mathrm{id}=67510112$

Escobar, G., 2012, "El uso de la teoría de la desorganización social para comprender la distribución de homicidios en Bogotá, Colombia", en Revista INVI, 27, 21 85. Recuperado de http://www.redalyc.org/articulo.oa?id=25823174002

ESRI, 2019, Métodos de clasificación, recuperado de https://doc.arcgis.com/es/ maps-for-office/4.0/design-and-use/classification-methods.htm 
Franco, S; Mercedes, C; Rozo, P; Gracia, G M; Gallo, G P; Vera, C Y; García, H. I., 2012, "Mortalidad por homicidio en Medellín, 1980-2007", en Ciência and Saúde Coletiva, 17, 3209-3218. Recuperado de http://www.redalyc.org/articulo. oa? $\mathrm{id}=63024424006$

Fuentes Flores, C. y Sánchez Salinas, O., 2015, “Contexto sociodemográfico de los homicidios en México DF: un análisis espacial", en Revista Panamericana de Salud Pública, 38, 450-456. Recuperado de https://www.scielosp.org/article/ rpsp/2015.v38n6/450-456/es/

Gaborit, M., 2005, "Los círculos de la violencia: violencia social y procesos comunitarios", en Pensamiento Psicológico, 1, 107-116. Recuperado de http://www. redalyc.org/articulo.oa? $\mathrm{id}=80100509$

Gasca, Francisco; Flores, Miguel, 2017, "Patterns of Spatiotemporal Distribution of Femicides in Mexico in 1990, 2000 and 2010", en Sociedad y Economía, 32, 15-40. Recuperado de http://www.scielo.org.co/scielo.php?script=sci_arttext\&pi$\mathrm{d}=\mathrm{S} 1657-63572017000100015$

González-Pérez, G J; Vega-López, M G; Cabrera-Pivaral, C E; Vega-López, A; Muñoz de la Torre, A., 2012, "Mortalidad por homicidios en México: tendencias, variaciones socio-geográficas y factores asociados", en Ciência and Saúde Coletiva, 17, 3195-3208. Recuperado de http://www.redalyc.org/articulo. oa? $\mathrm{id}=63024424005$

González-Pérez, G J; Vega-López, M G; Vega-López, A; Muñoz-De-La-Torre, A; Cabrera-Pivaral, C. E., 2009, "Homicidios de adolescentes en México, 19792005: evolución y variaciones sociogeográficas", en Papeles de Población, 15, 109-141. Recuperado de http://www.redalyc.org/articulo.oa?id=11212354004

Gutiérrez Cuéllar, P; Magdaleno del Río, G; Yáñez Rivas, V., 2010, "Violencia, Estado y crimen organizado en México", en El Cotidiano, 105-114. Recuperado de http://www.redalyc.org/articulo.oa?id=32515913013

Hernández-Bringas, H; Narro-Robles, J., 2010, "El homicidio en México, 20002008. Papeles de Población, 16, 243-271", en Recuperado de http://www.redalyc. org/articulo.oa? $\mathrm{id}=11213201009$

Huffschmid, Anne, 2015, "Huesos y humanidad. Antropología forense y su poder constituyente ante la desaparición forzada", en Athenea Digital. Revista de Pensamiento e Investigación Social vol. 15, núm. 3, noviembre, 2015. Recuperado de http://www.redalyc.org/articulo.oa?id=53742530009

INEGI, 2016, Marco Geoestadístico 2016, Instituto Nacional de Estadística Geografía e Informática. Recuperado de https://www.inegi.org.mx/app/biblioteca/ficha.html?upc $=702825217341$

Mata, L. J. y Solano Fernández, M., 2006, "Homicidio doloso en Costa Rica, 1993-2005: magnitud, tipología y tasas por país de origen del imputado", en Población y Salud en Mesoamérica, 4, Recuperado de http://www.redalyc.org/articulo.oa? id $=44640104$ 
Mendoza García, J., 2015, "Memoria de las desapariciones durante la guerra sucia en México", en Athenea Digital. Revista de Pensamiento e Investigación Social, 15 (3). Recuperado de http://www.redalyc.org/articulo.oa?id=53742530004

Meneses-Reyes, R; Fondevila, G., 2012, "Procesos y estructuras de una muerte violenta: homicidios en la Ciudad de México", en Papeles de Población, 18, 151202. Recuperado de http://www.redalyc.org/articulo.oa?id=11225471005

Monárrez Fragoso, J E; García de la Rosa, J., 2008, "Violencia e inseguridad en la frontera norte de México", en Nóesis. Revista de Ciencias Sociales y Humanidades 17, 42-65. Recuperado de http://www.redalyc.org/articulo.oa?id=85913301003

Morbiato, C., 2017, "Prácticas resistentes en el México de la desaparición forzada", en Trace. Travaux et Recherches dans les Amériques du Centre núm. 71, enero, 2017, pp. 138-165 Recuperado de: http://www.redalyc.org/articulo. oa? $\mathrm{id}=423850280006$

ONCSJL, 2018, Incidencia de los delitos de alto impacto en México 2017, México: Observatorio Nacional Ciudadano de Seguridad, Justicia y Legalidad (ONCSJL). Disponible en http://onc.org.mx/informe2017.pdf

Pantoja, S., 2019, "La PGJ de Garrido “maquilló" más de 29 mil delitos para justificar baja delictiva: Godoy", en Proceso 15/02/2019. Disponible en https://www. proceso.com.mx/572360/la-pgj-de-garrido-maquillo-mas-de-29-mil-delitos-para-justificar-baja-delictiva-godoy

Pereyra, G., 2015, "Violencia, desapariciones y catástrofe. México después de Ayotzinapa", en Argumentos, 28 vol. 28, núm. 78, abril, 2015, pp. 115-136. Recuperado de http://www.redalyc.org/articulo.oa?id=59541545013

Presidencia de la República, 2019, Conferencia de prensa del presidente Andrés Manuel López Obrador, del 7 de mayo de 2019. Disponible en https://www.gob. $\mathrm{mx} /$ presidencia/prensa/conferencia-de-prensa-del-presidente-andres-manuel-lopez-obrador-del-7-de-mayo-de-2019

Reveles, J., 2015, “México: país de desapariciones forzadas", en Política y Cultura, núm. 43, 2015, pp. 9-23. Recuperado de http://www.redalyc.org/articulo. oa? id $=26739871002$

Robledo Silvestre, C., 2016, “Genealogía e historia no resuelta de la desaparición forzada en México", en Iconos. Revista de Ciencias Sociales, núm. 55, 2016, pp. 93-114. Recuperado de: http://www.redalyc.org/articulo.oa?id=50945652005

Rodríguez Gázquez, María de los Ángeles, 2008, "Violencia homicida: clasificación y factores de riesgo", en Medicina U.P.B. vol. 27, núm. 2, julio-diciembre, 2008, pp. 125-139. Recuperado de www.redalyc.com/articulo.oa? $\mathrm{id}=159013081008$

Rodríguez Gázquez, María de los Ángeles, 2005, “Algunas características de la mortalidad por homicidio en Colombia. 1985 a 2001", en Revista Lasallista de Investigación, 2, 38-44. Recuperado de http://www.redalyc.org/articulo. oa? $\mathrm{id}=69520208$ 
Rodríguez, M., 2008, "Variación estacional de la mortalidad por homicidio en Colombia, 1985 a 2001", en Colombia Médica, 39, 154-160. Recuperado de http:// www.redalyc.org/articulo.oa? $\mathrm{id}=28339204$

Rojas Molina, Nelson, 2013, "Ley de víctimas y desaparición forzada en Colombia", en Revista Logos, Ciencia and Tecnología, vol. 5, núm. 1, julio-diciembre, 2013, pp. 39-50. Recuperado de http://www.redalyc.org/articulo.oa?id=517751547004

Sáenz Rojas, M. A., 2006, "Los homicidios dolosos en Costa Rica: caracterización sociodemográfica”, en Revista de Ciencias Sociales, I-II, 177-188. Recuperado de http://www.redalyc.org/articulo.oa?id=15311214

Salama, P., 2008, "Informe sobre la violencia en América Latina", en Revista de Economía Institucional, 10, 81-102. Recuperado de http:/www.redalyc.org/articulo.oa? id=41901804

Salama, P., 2013, “Homicidios, ¿es ineluctable la violencia en América Latina?”, en Frontera Norte, 25, 7-27. Recuperado de http://www.redalyc.org/articulo. oa? id=13625606001

Sánchez, R; Tejada, P; Martínez, J., 2005, "Comportamiento de las muertes violentas en Bogotá, 1997-2003”, en Revista de Salud Pública, 7, 254-267. Recuperado de http://sociales.redalyc.org/articulo.oa?id=42270302

SESNSP, 2019a, Incidencia delictiva. Secretariado Ejecutivo del Sistema Nacional de Seguridad Pública. Recuperado de https://www.gob.mx/sesnsp/acciones-y-programas/incidencia-delictiva-87005?idiom=es

SESNSP, 2019b, Registro Nacional de Datos de Personas Extraviadas o Desaparecidas, RNPED. Secretariado Ejecutivo del Sistema Nacional de Seguridad Pública. Recuperado de https://www.gob.mx/sesnsp/acciones-y-programas/registro-nacional-de-datos-de-personas-extraviadas-o-desaparecidas-rnped

Spinelli, H; Macías, G; Darraidou, V., 2008, "Procesos macroeconómicos y homicidios. Un estudio ecológico en los partidos del gran Buenos Aires (Argentina) entre los años 1989 y 2006", en Salud Colectiva, 4, 283-299. Recuperado de http:// www.redalyc.org/articulo.oa? $\mathrm{id}=73140303$

UNODC, 2011, 2011 Global Study On Homicide Trends, Contexts, Data, Viena: United Nations Office on Drugs and Crime. Recuperado de https://www.unodc. org/unodc/en/data-and-analysis/statistics/crime/global-study-on-homicide-2011. html

Vázquez, M., 2001, "Ser joven, ser varón, ser pobre. La mortalidad por causas violentas en los adolescentes del conurbano bonaerense", en Biblioteca Virtual, Consejo Latinoamericano de Ciencias Sociales, Clacso.

Vilalta Carlos J., 2013, "How Exactly Does Place Matter in Crime Analysis? Place, Space, and Spatial Heterogeneity", en Journal of Criminal Justice Education, 24:3, 290-315, http://dx.doi.org/10.1080/10511253.2012.715659

Vilalta, C and Muggah, R., 2016, "What Explains Criminal Violence in Mexico City? A Test of Two Theories of Crime. Stability", en International Journal of Security and Development, 5 (1): 1, pp. 1-22, DOI: http://dx.doi.org/10.5334/sta.433 
Vilalta, Carlos J. and Fondevila, Gustavo, 2019, "Modeling Crime in an Uptown Neighborhood: The Case of Santa Fe in Mexico City", en Papers in Applied Geography, https://doi.org/10.1080/23754931.2018.1554502

Vilalta, Carlos J., 2010, "Correlates of distance to crime in Mexico City, Global", en Crime, 11:3, 298-313. http://dx.doi.org/10.1080/17440572.2010.490634

Vilalta, Carlos J., José G. Castillo y Juan A. Torres, 2016, Delitos violentos en ciudades de América Latina: Banco Interamericano de Desarrollo

Villarreal Martínez, M., 2014, "Respuestas ciudadanas ante la desaparición de personas en México (2000-2013) ", en Espacios Públicos, 17 (39), http://www. redalyc.org/articulo.oa? $\mathrm{id}=67630574007$

Wang, Z., Lam, N. S., Obradovich, N., y Ye, X., 2019, “Are vulnerable communities digitally left behind in social responses to natural disasters? An evidence from Hurricane Sandy with Twitter data", en Applied Geography, 108, 1-8.

Zunino, M G; Spinelli, H; Alazraqui, M., 2006, "Muertes por armas de fuego: un eclipse en los Sistemas de Información en Salud", en Salud Colectiva, 2, 259-267. Recuperado de http://www.redalyc.org/articulo.oa?id=73120304

\section{RESUMEN CURRICULAR DE LOS AUTORES}

Edel Cadena Vargas

Sociólogo, Investigador Nacional. Profesor Investigador de la Universidad Autónoma del Estado de México UAEM desde 1985 y profesor visitante de diversas universidades México, Colombia y Argentina. Fundador de Convergencia revista de ciencias sociales, primera publicación de la UAEM en el Índice de Revistas Mexicanas de Investigación Científica y Tecnológica del Consejo Nacional de Ciencia y Tecnología Conacyt y en el Journal Citation Reports JCR. Evaluador del Programa Nacional de Posgrados PNPC del Conacyt. Fue también director de Quivera, revista de estudios territoriales.

Dirección electrónica: edelcadena@yahoo.com.mx

Registro ORCID: http://orcid.org/0000-0002-3131-9597

\section{Carlos Garrocho Rangel}

Investigador Nacional Nivel III. Evaluador del Sistema Nacional de Investigadores. Profesor-Investigador en El Colegio Mexiquense (desde 1986). Fundador y Director de la revista Economía, Sociedad y Territorio. Integrante Externo de la Comisión Dictaminadora del Centro de Investigaciones en Geografía Ambiental de la UNAM. Integrante del Consejo Consultivo Estratégico del CentroMet. Integrante de la Junta de Gobierno de El Colegio Mexiquense. Ganador del Premio Estatal de Ciencia y Tecnología 
del Estado de México en 2011. Ganador del Premio "Arch C. Gerlach" en 2017, que otorga cada cuatro años la Organización de los Estados Americanos a "la obra original de mayor valor e importancia para el desarrollo de la geografía de América." Distinguido desde 2018 por el Gobierno de la República del Paraguay como asesor internacional del CONCYT-Paraguay.

Dirección electrónica: carlosgarrochorangel@yahoo.com.mx

Registro ORCID: http://orcid.org/0000-0001-9181-3151

Artículo recibido el 25 de junio de 2019 y aprobado el 24 de noviembre de 2019. 